\title{
Frequência de consumo de frutas, hortaliças, produtos ultraprocessados e estado nutricional de gestantes de Cruzeiro do Sul, Acre.
}

\section{Ana Carolina Bonelá dos Santos}

Dissertação de Mestrado apresentada ao Programa de Pós-Graduação em Nutrição em Saúde Pública, como exigência para obtenção do título de Mestre em Ciências.

Área de concentração: Nutrição em Saúde Pública

Orientadora: Profa. Dra. Marly Augusto Cardoso

\section{Versão Corrigida}

São Paulo 
Dedico a conclusão deste trabalho ao grande Mestre Gabriel, que me levou para conhecer as mais belas cores da Amazônia, que coloriram meus dias solitários e me fortaleceram para seguir. 


\section{AGRADECIMENTOS}

Minha eterna gratidão a Deus, o Grande Rei do Universo, que com sua perfeição me conduziu para mais próximo dele, se mantendo sempre presente, me fortalecendo e irradiando luz na minha consciência.

Gratidão ao Mestre Gabriel, meu guia espiritual, amigo e anjo da guarda. Por ter me conduzido até a sua obra, pela presença e guarnição em minha vida. Por ter me proporcionado conhecer pessoas maravilhosas, queridas e irmãs.

Gratidão aos meus amigos e irmãos do Centro Espírita Beneficente União do Vegetal de Cruzeiro do Sul, pelo acolhimento extraordinário ao longo da minha estadia por lá. Pela amizade verdadeira, pelo carinho, por me fazer sentir parte dessa grande família, pelo colo, pela força e por todo amor a mim dedicado. De forma bem especial, aos irmãos do Núcleo Mestre Francisco, Mardia e Mello, que me acolheram em sua casa, me oferecendo muito carinho e uma amizade indescritível. À Verônica e ao Chico Gomes, pela amizade, pelos momentos de grandes risadas, força e palavras verdadeiras. À Catiana e ao Marcelo, por toda força, amizade e carinho. Às Marias e ao Hamilton e Nilton, à Railsa e ao Breno, à Rosa e ao Xirlians, à Oneide e ao Altamiro, à Alcione e ao Luís, à Flavia e ao Adriano pelas conversas, orientações, amizade e carinho. Às minhas queridas, Letícia, Samilly e Sanmady, que eu tive o grande prazer em conhecer no dia de São João e se tornaram valiosas amizades. Aos jovens André, Pâmela, Rayane, Luan, Mello Júnior e Seu Passos, pela amizade e alegria. Amo todos vocês!

Gratidão à minha família, pelo apoio incondicional, pela força, pela saudade sentida e alegria no meu retorno. Especialmente à minha mãe, exemplo de força, coragem, bondade e amor. Por não me deixar sem sua presença por um longo ano e ter encarado a viagem até o Acre, juntamente com minha irmã e meu sobrinho e me alegraram um tanto.

Gratidão à minha orientadora Marly Augusto, por ter me aceitado para trabalhar com sua pesquisa e por me abrir as portas da Universidade de São Paulo. Pelos desafios propostos, que me auxiliaram a traçar meu direcionamento profissional.

Gratidão imensa à Rosângela Augusto, querida Rô, que tive a honra de conhecer e trabalhar no primeiro ano que cheguei à São Paulo. Sem sua grande contribuição, força e energia transmitidas para mim, esse trabalho com certeza não seria concluído. Gratidão por cada 
palavra, abraço, ensino, luz e brilho minha querida amiga! Já aproveito para ser grata também a Fernanda Cobayashi e Aline Kurihayashi, que também conheci logo que cheguei à São Paulo e se tornaram grandes amigas dentro e fora da Universidade. Gratidão por toda a força e amizade. Adoro vocês três!

Sou grata também aos velhos e novos amigos, que me acompanham na jornada da vida e mais nessa etapa. Ivina, Tuani, Bárbara Carolyne, Vitória, Valéria, Marisa, amigos capixabas, valiosas pérolas que conquistei nos tempos da graduação e infância. Aos amigos e colegas que fiz ao longo da pós-graduação, Gustavo Dantas, Fabi, Evelyn, Rubens, Nádia, Naiá, Carlos David e Tânia, que acompanharam todo o meu processo dentro da pós-graduação e se tornaram queridos amigos para todas as horas.

Enorme gratidão à toda equipe de pesquisa, equipe fixa em São Paulo e em Cruzeiro do Sul, que dedicaram muito trabalho e empenho para realização da pesquisa. De forma bem especial ao Paulo Augusto, pela bondade, força e coragem que pude reconhecer nos seus olhos ao longo da minha estadia por Cruzeiro.

E a mais doce gratidão a quem teve o papel mais importante na efetivação dessa pesquisa, às gestantes que aceitaram fazer parte desse projeto, que dedicaram seu tempo para atender aos pesquisadores, com atenção e paciência. 
FONTES DE FINANCIAMENTO

O presente estudo integra um conjunto de pesquisas epidemiológicas sobre condições de saúde e nutrição materno-infantil em Cruzeiro do Sul, Acre, Amazônia Ocidental Brasileira: Materno-INfantil no Acre (MINA), em colaboração com a USP, a Universidade Federal do Acre (UFAC) e a Harvard T. H. Chan School of Public Health (HSPH). Com auxílio do Programa Ciência Sem Fronteiras, Chamada n $n^{\circ}$ 71/2013 do Conselho Nacional de Desenvolvimento Tecnológico $(\mathrm{CNPq})$, o Estudo MINA foi contemplado com auxílio à pesquisa e uma Bolsa Pesquisador Visitante Especial (PVE) para a Profa. Dra. Márcia Caldas de Castro da HSPH (processo CNPq $n^{\circ}$ 407255/2013-3). Recursos adicionais foram concedidos pela Fundação Maria Cecília Souto Vidigal e na Chamada PPSUS 001/2015 FAPAC - Programa Pesquisa para o SUS: Gestão Compartilhada em Saúde FAPAC/SESACRE/PPSUS MS/CNPq. Esta dissertação recebeu bolsa de mestrado do CNPq.

Membros da Coordenação MINA Study Working Group: Alícia Matijasevich Manitto (Departamento de Medicina Preventiva, Faculdade de Medicina da USP), Bárbara H. Lourenço e Suely G. A. Gimeno (Departamento de Medicina Preventiva, Escola Paulista de Medicina da Universidade Federal de São Paulo), Bruno Pereira da Silva e Rodrigo Medeiros de Souza (Universidade Federal do Acre - UFAC, campus da Floresta), Maíra B. Malta, Marly A. Cardoso, Paulo A. R. Neves (Departamento de Nutrição, Faculdade de Saúde Pública da USP) e Márcia C. Castro (Department of Global Health and Population, Harvard T. H. Chan School of Public Health). 
SANTOS, A.C.B. Frequência de consumo de frutas, hortaliças e produtos ultraprocessados e estado nutricional de gestantes de Cruzeiro do Sul, Acre. Dissertação (Mestrado) - Faculdade de Saúde Pública, Universidade de São Paulo, São Paulo, 2016.

Introdução - Ao longo das últimas décadas o mundo vivenciou grandes mudanças no padrão alimentar da população mundial, que resultou no aumento do consumo de produtos ultraprocessados e redução do consumo de frutas e hortaliças. No período gestacional, a nutrição materna exerce papel importante tanto em desfechos obstétricos como perinatais. $\mathrm{O}$ ganho de peso excessivo ou insuficiente e a deficiência de micronutrientes contribuem para complicações de curto e longo prazo para a mãe e para o bebê. Objetivo - Investigar a associação entre frequência de consumo de frutas, hortaliças e produtos ultraprocessados e indicadores do estado nutricional em gestantes de Cruzeiro do Sul. Métodos - Trata-se de uma análise transversal dos dados de estudo de coorte de gestantes inscritas no pré-natal da atenção básica à saúde na área urbana da cidade de Cruzeiro do Sul, estado do Acre, Amazônia Ocidental Brasileira. Entre fevereiro de 2015 a janeiro de 2016 foram coletados dados socioeconômicos e obstétricos (obtidos por entrevista domiciliar até a $20^{\mathrm{a}}$ semana gestacional) e antropométricos, bioquímicos e dietéticos maternos (obtidos na $1^{\text {a }}$ avaliação clínica, entre a $16^{\mathrm{a}}$ e $20^{\mathrm{a}}$ semana de gestação, realizada na unidade de saúde). O estado nutricional foi avaliado pela frequência de anemia (hemoglobina sanguínea $<110 \mathrm{~g} / \mathrm{L}$ ), deficiência de vitamina A (retinol sérico $<0,70 \mu \mathrm{mol} / \mathrm{L}$ ), concentrações séricas de vitamina $\mathrm{E}$, ácido fólico e $\beta$-caroteno e índice de massa corporal (IMC, $\mathrm{kg} / \mathrm{m}^{2}$ ) pré-gestacional autoreferido. A associação entre variáveis categóricas foi investigada por meio do teste do QuiQuadrado de Pearson e comparações entre variáveis contínuas foram realizadas pelo teste de 
Mann Whitney. Resultados - Dentre as 860 gestantes rastreadas, 183 eram não elegíveis e 171 houve perda de contato para o estudo. Portanto, para a presente análise, foram incluídas 506 gestantes, das quais $26 \%$ eram adolescentes (<20 anos), $44 \%$ primigestas e $76 \%$ referiram cor de pele parda. Anemia e deficiência de vitamina A foram observadas em $15,4 \%$ e $10,9 \%$ das gestantes estudadas, respectivamente. No total, as frequências de baixo peso (IMC $<18,5 \mathrm{~kg} / \mathrm{m}^{2}$ ) e excesso de peso (IMC $\geq 25 \mathrm{~kg} / \mathrm{m}^{2}$ ) segundo IMC pré-gestacional foram 10,1\% e 30,7\%, respectivamente. Concentrações séricas abaixo das medianas de $\beta$-caroteno, vitamina $\mathrm{E}$ e folato foram associadas à menor idade $(<20$ anos $)$, menor escolaridade $(<10$ anos), ser beneficiária do programa bolsa família e ser chefe de família. Anemia e deficiência de vitamina A foram também associadas à menor idade, menor escolaridade e menor IMC pré-gestacional. Gestantes com consumo diário de frutas e hortaliças apresentaram maiores concentrações séricas (mediana; intervalo interquartil em $\mu$ mol/L) de $\beta$-caroteno $(0,50 ; 0,30$ 0,84) e vitamina A $(1,90 ; 1,10-2,70)$ quando comparadas às gestantes sem consumo diário desses alimentos, para $\beta$-caroteno $(0.40 ; 022-0.76)$ e vitamina A séricos $(1,70 ; 1,00-2,50)$. Não houve associação entre consumo de produtos ultraprocessados e os indicadores bioquímicos avaliados. Conclusões - Na presente população de estudo, características sócio demográficas foram associadas ao estado nutricional no segundo trimestre gestacional. $\mathrm{O}$ consumo diário de frutas e hortaliças influenciou positivamente as concentrações séricas de $\beta$ caroteno e vitamina A das gestantes. Esses resultados reforçam a importância de programas de promoção social integrados `as ações para incentivo à alimentação saudável visando à melhoria das condições de saúde materna.

Descritores: Nutrição materna, dieta, consumo de alimentos, estado nutricional. 
SANTOS, A.C.B. Frequency of consumption of fruits, vegetables and ultra-processed products and nutritional status of pregnant women in Cruzeiro do Sul, Acre. 2016 (Master thesis) - School of Public Health, University of São Paulo, São Paulo, 2016.

Introduction - Over the past decades we have seen major changes in dietary patterns of the worldwide population, with an increasing consumption of ultra-processed products and low consumption of fruits and vegetables. During pregnancy, maternal nutrition plays an important role on both obstetric and perinatal health outcomes. Excessive or insufficient weight gain and micronutrient deficiencies also contribute to short and long-term complications for both mother and baby. Objective - To investigate the association among frequency of consumption of fruits, vegetables and ultra-processed products and nutritional status indicators of pregnant women in Cruzeiro do Sul. Methods - This is a cross-sectional data analysis of pregnant women, who were part of a cohort study of prenatal at primary health care in the urban area of Cruzeiro do Sul, Acre state, Brazilian Western Amazon. From February 2015 to January 2016 socioeconomic and obstetric data were collected through home interviews and anthropometric, biochemical and maternal diet were obtained on the $1^{\text {st }}$ clinical evaluation, amongst $16^{\text {th }}$ and $20^{\text {th }}$ pregnancy weeks, conducted in local health unit. Nutritional status was assessed through prevalence of anemia (blood hemoglobin $<110 \mathrm{~g} / \mathrm{L}$ ), vitamin A deficiency (serum retinol $<0,70 \mu \mathrm{mol} / \mathrm{L}$ ), serum concentrations of vitamin $\mathrm{E}$, folic acid and $\beta$-carotene and self-reported pre-pregnancy Body Mass Index (BMI, $\mathrm{kg} / \mathrm{m}^{2}$ ). The association between categorical variables was considered by using the chi-square test of Pearson and comparisons between continuous variables were conducted using the Mann Whitney test. Results: Overall, 860 pregnant women were screened; of them, 183 was ineligible for the study and 171 were lost during follow-up. Thus, the final number for this analysis was 506 pregnant women: $26 \%$ were adolescents ( $<20$ years), $44 \%$ were at first- 
pregnancy and $76 \%$ reported brown skin color. Anemia and vitamin A deficiency were observed in $15.4 \%$ and $10.9 \%$ in the sample, respectively. The frequency of low body weight $\left(\mathrm{BMI}<18,5 \mathrm{~kg} / \mathrm{m}^{2}\right)$ and overweight $\left(\mathrm{BMI} \geq 25 \mathrm{~kg} / \mathrm{m}^{2}\right)$ according to the pre-pregnancy BMI were $10.1 \%$ and $30.7 \%$, respectively. Serum concentrations below the median values for $\beta$ carotene, vitamin E and folate were associated with younger age ( $<20$ years), lower schooling years $(<10$ years), beneficiary of the Cash Transfer Program (Bolsa Família), and when the pregnant woman is the householder of the family. Anemia and vitamin A deficiency were associated with younger age, less education and lower pre-pregnancy BMI. Pregnant women with daily consumption of fruits and vegetables had higher serum concentrations (median, interquartile range in $\mathrm{mmol} / \mathrm{L})$ of $\beta$-carotene $(0.50,0.30$ to 0.84$)$ and vitamin $\mathrm{A}(1.90,1.10$ 2.70) compared with those who did not have daily consumption of these foods, for both serum concentrations of $\beta$-carotene $(0: 40 ; 022-0.76)$ and vitamin $\mathrm{A}(1.70 ; 1.00$ to 2.50$)$. There was no association between consumption of ultra-processed products and biochemical indicators. Conclusions - In this study population, sociodemographic characteristics were associated with nutritional status in the second trimester of pregnancy. The daily consumption of fruits and vegetables positively influenced serum concentrations of $\beta$-carotene and vitamin $A$ in pregnant women. These results emphasize the importance of social support programs for scaling up nutrition interventions in order to improve maternal health status.

Keywords: Maternal nutrition, diet, food consumption, nutritional status. 


\section{Sumário}

1 - Introdução........................................................................................................................... 11

1.1 - Consumo de frutas e hortaliç̧as.............................................................. 12

1.2 - Consumo de Ultraprocessados................................................................ 15

1.3 - Consequências do consumo alimentar inadequado durante a

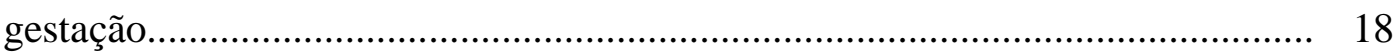

1.4 - Estratégias para prevenção de deficiências nutricionais em gestantes....... 23

2 - Justificativa........................................................................................................................ 26

3 - Objetivos........................................................................................................................................ 27

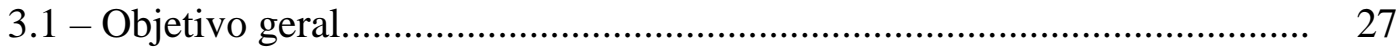

3.2 - Objetivos específicos........................................................................ 27

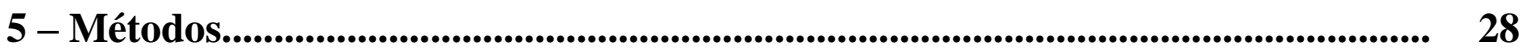

5.1 - Área do estudo............................................................................... 28

5.2 - Delineamento, população de estudo e aspectos éticos............................ 30

5.3 - Caracterização das condições sócio demográficas, obstétricas e estilo de vida.

5.4 - Avaliação antropométrica.................................................................... 33

5.5 - Avaliação do consumo alimentar.............................................................. 33

5.6 - Avaliação dos parâmetros bioquímicos.................................................. 34

5.7 - Análise dos dados.......................................................................... $\quad 35$

6 - Resultados............................................................................................................................. 37

6.1 - Apresentação das gestantes rastreadas, elegíveis ao estudo e perdas de seguimento.

6.2 - Caracterização das gestantes segundo variáveis socioeconômicas, antropométricas, pressão arterial e de estilo de vida.

6.3 - Indicadores bioquímicos do estado nutricional das gestantes estudadas.

6.4 - Associação entre características sócio demográficas e antropométricas das gestantes, segundo deficiência de vitamina A (DVA), anemia e valores de folato, $\beta$-caroteno e vitamina $E$ séricas abaixo da mediana.

6.5 - Associação entre frequência de consumo diário de frutas e hortaliças (FH) e produtos ultraprocessados (UP), características sócio demográficas e concentração de hemoglobina sanguínea e vitaminas séricas. 
7 - Discussão....................................................................................................................... 48

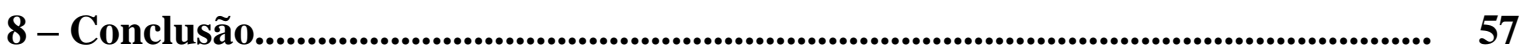

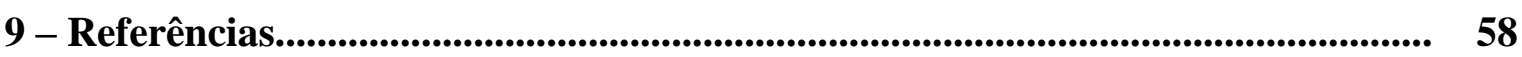

10 - Anexos................................................................................................................ 65

10.1 - Anexo 1. Ficha para rastreamento das gestantes pelos postos de

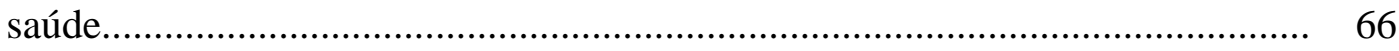

10.2 - Anexo 2. Questionário sócio demográfico e de história de saúde............ 68

10.3 - Anexo 3. Questionário da avaliação clínica para dados

antropométricos, bioquímicos, de consumo alimentar e ultrassonografia............ 75

10.4 - Anexo 4. Termo de Consentimento Livre e esclarecido............................. 82

11 - Currículos Lattes.................................................................................................... 85 


\section{1 - Introdução}

Ao longo das últimas décadas o mundo vivenciou grandes mudanças no padrão alimentar da população, que resultou no aumento do consumo de alimentos altamente processados e redução de alimentos considerados de importante valor nutricional, como frutas e hortaliças. Essas mudanças começaram em países desenvolvidos e hoje os países em desenvolvimento compartilham a mesma realidade (POPKIN, 2011). Alterações dietéticas em conjunto com outras mudanças sociais que resultam em menor nível de atividade física (como urbanização, industrialização e desenvolvimento econômico), têm forte impacto no estado de saúde das populações e estão relacionadas ao aumento de doenças crônicas não transmissíveis, como obesidade, doenças cardiovasculares, diabetes tipo 2 e alguns tipos de câncer (WHO, 2003; WANG et al., 2014).

É consenso na literatura que a nutrição materna tem influências sobre os desfechos gestacionais para a mãe e para o bebê (BRUNST et al., 2014; HILLESUND et al., 2014; CHEN et al., 2013). O consumo energético antes e durante a gestação é um importante determinante do ganho de peso gestacional, pois tanto o ganho excessivo quanto insuficiente pode acarretar efeitos adversos à saúde materna e infantil. O ganho excessivo de peso tem sido associado à macrossomia, complicações no parto, obesidade, resistência à insulina e síndrome metabólica na criança. Já o ganho de peso insuficiente tem sido associado à restrição de crescimento intrauterino e baixo peso ao nascer (LACERDA et al., 2007; HILLESUND et al., 2014). E em relação ao consumo de micronutrientes, a deficiência materna de ferro, ácido fólico, zinco, vitamina B12, dentre outros, há muitas décadas é conhecida como importante determinante do baixo peso ao nascer, além de poder causar prejuízos a saúde materna (KRAMER, 1987). 


\section{1 - Consumo de frutas e hortaliças}

O consumo de frutas e hortaliças é essencial para o suprimento de micronutrientes ao organismo humano. Evidências científicas sugerem que o consumo regular de frutas e hortaliças tem efeito protetor para doenças crônicas não transmissíveis (WHO, 2003; HE et al., 2006; BÜCHNER et al., 2010, HU et al., 2014). Portanto, a Organização Mundial de Saúde (OMS) recomenda o consumo de aproximadamente 400g de frutas e hortaliças por dia (cinco porções), como uma das estratégias para prevenção de doenças crônicas não transmissíveis (WHO, 2003).

O baixo consumo desses alimentos, principalmente nos países em desenvolvimento, tem sido preocupante e alvo de pesquisas nas últimas décadas. De acordo com a OMS, apenas 6 das 14 regiões quando investigadas, tinham disponibilidade de frutas e hortaliças iguais ou superiores à recomendação (WHO, 2003). Para citar um exemplo, na Índia dados de amostra representativa do país, indicam que no início da década passada o consumo médio de frutas e hortaliças era de aproximadamente 140g/per capita. No início dessa década, houve melhoria do consumo médio, praticamente dobrando a quantidade (301g/per capita), porém, ainda se encontra abaixo do recomendado (SACHDEVA et al., 2013).

Mesmo em países desenvolvidos, como Estados Unidos, ainda é um desafio aumentar o consumo de frutas e hortaliças. Em 2009 a proporção de adultos norte-americanos que consumiam dentro da recomendação da OMS era de 32,5\% para o consumo de frutas e 26,3\% para o consumo de hortaliças (CDC, 2010).

O padrão alimentar no Brasil também mudou nas últimas décadas. Estudos que avaliaram dados de pesquisas de orçamentos familiares (POF), segundo regiões metropolitanas do Brasil, mostram a participação cada vez maior de produtos industrializados na dieta dos brasileiros, e em consequência, a redução de consumo dos alimentos in natura ou 
minimamente processados, que são o arroz e feijão, carnes, leite e ovos, frutas e hortaliças, raízes e tubérculos, entre outros (MARTINS et al., 2013; MONTEIRO et al., 2014).

De acordo com os dados da última POF (2008-09), a média de consumo per capita de frutas e hortaliças no Brasil é de $153 \mathrm{~g}$, variando entre as regiões, entre as classes sociais e entre a população urbana e rural. A região Norte, por exemplo, apresenta o menor consumo $(109 \mathrm{~g} / \mathrm{per}$ capita) e mesmo na região Sul, com maiores médias de consumo desse grupo de alimentos (205g/per capita), a quantidade ainda está muito aquém da recomendação estabelecida pela OMS (IBGE, 2010).

No Rio de Janeiro, por exemplo, um estudo de coorte de gestantes atendidas em serviços de saúde, observou ingestão excessiva de calorias e baixo consumo de micronutrientes. Uma situação que é causada pelo baixo consumo de frutas e hortaliças e alto consumo de produtos processados (LACERDA et al., 2007).

O consumo de frutas e hortaliças por gestantes em países desenvolvidos é consideravelmente superior ao consumo de gestantes residentes em países em desenvolvimento. Estudo sobre o impacto da dieta durante a gestação na saúde da criança, conduzido em cinco países da Europa, mostra que o consumo médio per capita de frutas e hortaliças foi de $579 \mathrm{~g}$, maior que o recomendado pela OMS (PEDERSEN et al., 2013).

No Brasil não há muitos dados disponíveis sobre o consumo alimentar de gestantes. Um estudo que analisou os dados de consumo de 322 gestantes incluídas na POF 2008-2009 e comparou com o consumo alimentar de mulheres em idade fértil, relata não ter encontrado diferenças significativas entre esses dois grupos. Portanto, o consumo referido de $153 \mathrm{~g}$ de frutas e hortaliças, encontrado pela POF para a média nacional, seria a mesma quantidade de consumo para gestantes (SANTOS et al., 2014). 
Outro estudo realizado com 82 gestantes de cinco unidades básicas de saúde do município de São Paulo, utilizando inquérito recordatório alimentar de 24 horas, encontrou consumo médio diário de frutas, legumes e verduras de 335,7g, (MARTINS e BENÍCIO, 2011). Entretanto, esses dados de consumo podem não ter validade externa devido ao tamanho amostral e por ser uma amostra homogênea, principalmente, a respeito de escolaridade, presença de companheiro no domicílio e renda.

Dados semelhantes foram encontrados em estudo longitudinal realizado em centro de saúde do Rio de Janeiro, com 467 gestantes. Através do questionário de frequência de consumo alimentar semi-quantitativo, foi encontrado consumo médio de 354,16g de frutas e hortaliças. Entretanto, em análise do consumo estratificado por cor da pele, houve diferenças significantes para o consumo de frutas entre brancas e pardas (LACERDA et al., 2007).

Os dados disponíveis em inquéritos populacionais podem apresentar discrepâncias importantes dependendo dos métodos de avaliação do consumo de alimentos, como sugere estudo sobre diferenças entre estimativas de consumo de frutas e hortaliças na cidade de São Paulo em 2002-2003 (CLARO et al., 2010). Os autores concluíram que os métodos baseados na oferta ou disponibilidade de frutas e hortaliças tendem a superestimar a ingestão individual desses alimentos. Entretanto, os dados mostrados nos parágrafos anteriores relativos a gestantes de apenas dois estados da região sudeste em pequenas amostras não são condizentes com essa conclusão. As estimativas de consumo mensurado através de dados de oferta e ingestão de alimentos das POFs observaram quantidades menores quando comparadas aos dados de inquéritos individuais estimados por recordatórios de 24 horas e questionário de frequência alimentar. 


\section{2 - Consumo de ultraprocessados}

Atualmente, muito tem se falado sobre o processamento de alimentos e a participação destes na dieta da população. Lançado em 2014, o guia alimentar brasileiro ganhou destaque mundial por propor a classificação dos alimentos através do processamento a que são submetidos.

A classificação segue o seguinte formato: Grupo 1 - Alimentos in natura ou minimamente processados, que são partes comestíveis de plantas, animais e também água, alga e cogumelos. Esses alimentos podem passar por processamento simples para remoção de partes não comestíveis. Frutas, legumes, verduras, arroz, feijão, grãos e leguminosas fazem parte deste grupo. Grupo 2 - Ingredientes culinários processados, são substâncias extraídas do grupo 1 ou da natureza, para servirem de ingredientes para preparação de pratos salgados, doces, sopas, saladas, conservas, pães caseiros e etc. São exemplos desse grupo, sal de cozinha, açúcar, melado, mel, óleos, gorduras e vinagres. Grupo 3 - Alimentos processados, que são produtos fabricados com adição de sal, açúcar, óleo, vinagre e/ou outras substâncias referente ao grupo 2. Esse grupo normalmente tem dois ou três ingredientes. O objetivo desse processamento é aumentar a durabilidade dos alimentos in natura ou minimamente processados. São exemplos desse grupo, conserva de legumes, de cereais ou leguminosas, castanhas com sal ou açúcar, carnes salgadas, peixe em conserva, frutas em calda, queijos e pães. Grupo 4 - Alimentos ultraprocessados, onde estão inclusas formulações industriais, que normalmente são produzidas a partir de cinco ou mais ingredientes. Usualmente este grupo inclui substâncias e aditivos também utilizados no grupo 3, mas tem a peculiaridade de utilizar substâncias não usuais e aditivos que objetivam simular atributos sensoriais de alimentos do grupo 1 e ou ocultar atributos sensoriais indesejáveis. Nessas formulações industriais, os alimentos do grupo 1 normalmente encontram-se em porção mínima ou nem 
estão presentes nos ingredientes. O objetivo desse grau de processamento é criar produtos pronto para o consumo, com um apelo comercial através de publicidade, embalagem e preço, além da principal característica que é a hiperpalatabilidade. São exemplos desse grupo, refrigerantes e bebidas açucaradas, salgadinhos de pacote, sorvetes, chocolates, balas, biscoitos recheados, pães de forma, bolos, cereais matinais, barras de cereal, achocolatados, caldos de carne, frango e legumes, maionese, fórmulas infantis, produtos congelados prontos para aquecer, hambúrguer, salsicha, sopas e macarrão instantâneos (MONTEIRO et al., 2010; MONTEIRO et al., 2016)

Com a repercussão mundial do guia alimentar brasileiro, países de todo o mundo têm utilizado a classificação proposta para realização de estudos relacionados à saúde de sua população, como Estados Unidos, Canadá, Reino Unido, Nova Zelândia, Chile e Suécia. Os resultados obtidos nestes estudos evidenciam o crescimento na produção e consumo de alimentos ultraprocessados e redução dos alimentos in natura ou minimamente processados e preparações culinárias. Também fica evidente a relação do aumento da obesidade e outras doenças crônicas com esse tipo de alimentação (MONTEIRO et al., 2016).

Nos Estados Unidos, por exemplo, em estudo transversal utilizando os dados nacionais de saúde e nutrição de 2009-2010, em que foram avaliados pelo menos um recordatório de 9.317 participantes, observou que os alimentos ultraprocessados compõe $57,9 \%$ do consumo de energia e contribui para 89,7\% da ingestão de açúcar adicional (MARTINEZ et al., 2016).

No Chile, um estudo com amostra nacional representativa com 10.096 famílias do $6^{\circ}$ inquérito de orçamentos familiares e despesas, observou que o consumo de alimentos ultraprocessados compõe $55 \%$ do total de energia do cardápio dos Chilenos, sendo que essa proporção ainda aumenta de acordo com a renda (CROVETTO et al., 2014) 
No Brasil, estudo realizado a partir de dados de aquisição de alimentos através de pesquisas coordenadas pelo Instituto Brasileiro de Geografia e Estatística (IBGE) em 4 períodos: 19871988, 1995-1996, 2002-2003 e 2008-2009, observou o aumento expressivo da contribuição energética dos alimentos ultraprocessados de acordo com os anos analisados. Sendo que, de 2002 até 2009 esse aumento foi de 20,8\% para 25,4\% e redução da participação calórica dos alimentos in natura e minimamente processados e de ingredientes culinários (MARTINS et al., 2013)

Essa grande participação de produtos ultraprocessados na dieta da população é preocupante, devido a sua inadequada composição nutricional, geralmente pobre em fibras, rica em açúcares, gorduras não saudáveis e sódio, que resultam em desequilíbrios nutricionais quando consumidos em excesso ou em substituição a alimentos in natura ou minimamente processados.

Como mostra um estudo realizado a partir de dados da POF 2008-2009, em que foram avaliados os alimentos consumidos por 34.003 indivíduos, em dois recordatórios de dias não consecutivos. Depois de classificar os alimentos de acordo com o guia alimentar, 17 micronutrientes foram avaliados e para 16 deles, a quantidade consumida se encontrava abaixo dos parâmetros recomendados.

Embora a deficiência de micronutrientes pode não se manifestar clinicamente, a deficiência subclínica pode ser prejudicial à saúde. Muitos micronutrientes como ferro, zinco, vitamina B12, vitamina $\mathrm{C}$, riboflavina e selênio podem agir como imunomoduladores reduzindo a suscetibilidade a doenças infecciosas e seus agravantes. Outros micronutrientes são de extrema importância para manutenção e desenvolvimento da massa óssea, como vitamina D, cálcio, fosforo e magnésio e as vitaminas do complexo B estão envolvidas na função cognitiva dos indivíduos (LOUZADA et al., 2015). 


\section{3 - Consequências do consumo alimentar inadequado durante a gestação}

A gestação é uma fase em que o organismo materno passa por processos fisiológicos que levam a alterações importantes nos órgãos e vias metabólicas. Essas alterações são: aumento do volume plasmático, aumento da massa de hemoglobina, aumento dos níveis séricos de estrógeno, progesterona e hormônios placentários e também alterações nas funções respiratórias, gastrintestinais e geniturinárias (MONTEIRO e JUNIOR, 2007).

Durante os três trimestres da gestação, os aspectos fisiológicos, metabólicos e nutricionais são diferentes, pois as demandas do feto se modificam. Durante o primeiro trimestre gestacional, o feto depende da condição nutricional pré-gestacional da mãe, de suas reservas energéticas e de vitaminas e minerais. Essa dependência do estado nutricional pré-gestacional explica que mesmo havendo alterações hormonais que levam a enjoo e vômitos, que podem levar a perda de peso nesta fase, o feto não sofre prejuízos.

Já no segundo trimestre, o meio externo tem grande influência na condição nutricional da mãe e do feto, pois o fator emocional, de estilo de vida e nutricional são importantes para o ganho de peso da mãe e do bebê (VÍTOLO, 2008). Em estudo de coorte de gestantes realizado no Chile, por exemplo, em que foram comparadas mulheres que desenvolveram diabetes no segundo trimestre gestacional e mulheres que não desenvolveram diabetes gestacional, foi encontrada associação positiva entre maior ganho de peso e desenvolvimento de diabetes gestacional no segundo trimestre. Além disso, foi observado que os bebês de mães que desenvolveram diabetes gestacional no segundo trimestre apresentaram mais complicações do que os bebês de mães que não desenvolveram diabetes gestacional no segundo trimestre, apesar desse dado não apresentar significância estatística para aquela população, é um fator importante a ser ressaltado (HUIDOBRO et al., 2010). 
Também explica a importância da condição nutricional no segundo trimestre, um outro estudo de coorte de gestantes realizado na China, em que foi estudado a associação entre ingestão alimentar e composição corporal e risco para desenvolvimento de diabetes gestacional no segundo trimestre. Foi observado que gestantes que tinham maior consumo de energia, proteína e gordura, tiveram maior risco de desenvolver diabetes gestacional do que gestantes que apresentavam consumo menor desses grupos de alimentos (QUING et al., 2016)

Porém, o consumo alimentar durante a gestação é influenciado pelas várias mudanças no comportamento alimentar da população, como discutido acima, mas também influenciadas por crenças arraigadas da sociedade de que o consumo energético deve aumentar excessivamente durante essa fase. Diferente de mulheres em idade fértil, o ganho de peso durante a gestação tem outro significado social, que faz com que as mulheres grávidas pouco se preocupem com o peso ponderal, o que gera certo conflito entre saber popular e científico, como discutido por KRASCHNEWSKI E CHUANG (2014).

No entanto, o consumo alimentar, especialmente dietas ricas em produtos ultraprocessados e pobres em frutas, vegetais e cereais integrais, tem sido associado ao aumento de peso na população em geral. Resultados da análise de três grandes estudos prospectivos de coorte norte americana encontraram associação positiva entre o aumento do consumo de alguns grupos de alimentos (batata frita, bebidas açucaradas, batatas em geral, carnes vermelhas processadas e não processadas) com o ganho de peso. Também foi observado que o aumento do consumo de legumes, grãos integrais, frutas, nozes e iogurte foi inversamente associado ao ganho de peso (MOZAFFARIAN et al., 2011).

Em relação às gestantes, estudos de coorte têm demonstrado que o consumo alimentar exerce forte influência no ganho de peso gestacional (LACERDA et al., 2007; HILLESUND et al., 2014). Como por exemplo, um estudo de coorte prospectivo de base populacional realizado na 
Noruega, que avaliou a adesão da dieta nórdica (rica em frutas e legumes, cereais integrais, batata, peixe, caça, leite e água potável) entre gestantes e a associação desta dieta com o ganho de peso gestacional. A adesão à dieta nórdica foi classificada em baixa, média e alta, de acordo com o questionário de frequência alimentar. As mulheres categorizadas com maior adesão a dieta nórdica, tiveram o consumo diário médio de cerca de seis porções de frutas e vegetais, quase o dobro do que aqueles com baixa adesão a dieta nórdica. Este estudo concluiu que a alta adesão a esta dieta, pode facilitar o ganho de peso gestacional recomendado, em mulheres que iniciam a gestação com Índice de Massa Corporal (IMC) adequado (HILLESUND et al., 2014)

Este ganho de peso ideal se refere ao ganho de peso gestacional recomendado pelo Instituto de Medicina dos Estados Unidos (IOM), que toma por base a avaliação do estado nutricional antropométrico no início da gestação, utilizando a seguinte classificação da OMS (1995): Baixo peso (IMC $<18,5 \mathrm{~kg} / \mathrm{m}^{2}$ ); Adequado (IMC $\geq 18,5-\leq 24,9 \mathrm{~kg} / \mathrm{m}^{2}$ ); Sobrepeso (IMC $\left.\geq 25,0-\leq 29,9 \mathrm{~kg} / \mathrm{m}^{2}\right)$ e Obesidade $\left(\geq 30 \mathrm{~kg} / \mathrm{m}^{2}\right)$. A partir desta classificação, o IOM sugere ganho de peso gestacional de: $12,5 \mathrm{Kg}-18,0 \mathrm{Kg}$ para mulheres com baixo peso; $11,5 \mathrm{Kg}-$ 16,0 Kg para mulheres com o peso adequado; 7,0 Kg - 11,5 Kg para mulheres com sobrepeso e 5,0 Kg - 9,0 Kg para mulheres obesas (IOM, 2013).

É bem documentado na literatura que o ganho de peso materno tem influência no peso ao nascer e que o ganho de peso adequado durante a gestação está relacionado a desfecho fetal satisfatório (KAC E MELÉNDEZ, 2005). No entanto, ganho de peso materno insuficiente é apontado há muito tempo, em resultado de metanálise, como um dos determinantes para o baixo peso ao nascer, que por sua vez é um importante fator para mortalidade neonatal (KRAMER, 1987). 
Já o ganho de peso excessivo durante a gestação foi relacionado, em estudo prospectivo de coorte multicêntrico, a complicações importantes como hemorragia no parto normal, infecções, prematuridade e morte perinatal no parto cesárea, além do risco aumentado para este tipo de parto (SELIGMAN et al., 2006). Também foi demonstrado em outro estudo de coorte prospectivo de base populacional referente ao nordeste da Itália, com informações referente a mais de quinze mil partos, que o risco para macrossomia é 1,6 vezes maior em bebês de mulheres que tiveram ganho de peso excessivo durante a gestação quando comparado a bebês de mulheres que ganharam peso adequado (ALBERICO et al., 2014).

O ganho de peso excessivo durante a gestação e o estado nutricional pré-gestacional de obesidade também são fatores de risco para o desenvolvimento de diabetes gestacional. Em uma coorte de nascimentos de base populacional realizada em Pelotas, Rio Grande do Sul, foi observado que mulheres obesas tiveram o risco para desenvolver diabetes gestacional duas vezes e meia maior que mulheres de menor IMC. Este resultado refere-se somente ao IMC pré-gestacional, pois o ganho de peso durante a gestação não pôde ser analisado nesta pesquisa por causa das perdas de informação de seguimento (DODE e SANTOS, 2009).

Sustenta esses achados um estudo realizado na China, onde o registro de saúde de mais de trinta mil gestantes e seus filhos foram analisados. Nesse estudo, foi observado que mulheres com obesidade pré-gestacional e ganho de peso excessivo na gestação apresentaram maiores riscos de desenvolver diabetes gestacional, hipertensão induzida pela gravidez e parto por cesariana em comparação com mulheres com IMC pré-gestacional normal e ganho de peso adequado (LI et al., 2013).

Alguns desses desfechos desfavoráveis também foram observados por um estudo de coorte de base populacional realizado em uma província do Canadá, onde mulheres que iniciaram a gestação com IMC adequado e tiveram ganho de peso excessivo durante a gestação foi 
associado ao risco de hipertensão na gestação, macrossomia, maior tempo de internação e anormalidade metabólica neonatal. Já em mulheres que iniciaram a gestação com excesso de peso, o ganho de peso excessivo durante a gestação foi associado também à hipertensão gestacional, macrossomia e tendência a maior indução do parto e para as que iniciaram a gestação com obesidade e com ganho excessivo de peso, houve risco para macrossomia, anormalidade metabólica neonatal e cesariana (CRANE et al., 2009).

Dados publicados referentes à coorte das enfermeiras acompanhadas desde a década de 1980 nos Estados Unidos mostram com maior clareza a magnitude da associação entre IMC prégestacional, dieta e desenvolvimento de diabetes gestacional. Nesse estudo, o fator individual que apresentou maior risco para o desenvolvimento de diabetes gestacional foi o IMC prégestacional elevado, demonstrando relação linear positiva entre tais variáveis. Fatores relacionados ao estilo de vida antes da gravidez como atividade física, tabagismo e dieta saudável (maior consumo de frutas e hortaliças, nozes, grãos integrais, ácidos graxos poliinsaturados, ácidos graxos ômega 3 e menor ingestão de carnes vermelhas, alimentos processados, açúcar, bebidas adoçadas, gorduras trans e sódio) também foram associados ao risco para diabetes gestacional, mesmo ajustando por fatores de risco para o desenvolvimento desta doença (ZANG et al., 2014).

Em relação à deficiência de micronutrientes, como o ferro, estima-se que mais da metade de mulheres grávidas tenham anemia por deficiência de ferro em países em desenvolvimento. A deficiência desse mineral está associada a vários efeitos adversos para a mãe e bebê, incluindo aumento do risco de hemorragia, sepse, mortalidade materna, mortalidade perinatal e baixo peso ao nascer (WHO, 2001).

A deficiência de vitamina A durante a gestação também está relacionada a resultados adversos, como anemia, desnutrição, infecção do trato urinário e no sistema reprodutivo, 
diarreia, pré-eclâmpsia e eclampsia, sintomas gastrointestinais (vômitos e náuseas) e inapetência alimentar, o que pode aumentar a chance de óbitos para mãe e bebê (CHRISTIAN et al., 1998).

Um estudo transversal de base populacional, realizado com mais de vinte mil mulheres etíopes em idade fértil, sugere que a anemia está relacionada com a deficiência de ferro e ácido fólico e possivelmente com a de outros micronutrientes. Neste estudo, os autores compararam diversas características de mulheres anêmicas e não anêmicas e encontraram menor consumo de frutas, legumes e alimentos de origem animal no grupo de mulheres anêmicas. Portanto, sugerem que as estratégias de suplementação devem levar em conta também programas de educação nutricional para prevenção das deficiências de micronutrientes como um todo e assim melhorar os resultados adversos da gestação (HAIDAR, 2010).

\section{4 - Estratégias para Prevenção de Deficiências Nutricionais em Gestantes}

Com base nas evidências disponíveis e a partir da definição de questões prioritárias para atuação em saúde pública, a OMS formulou diretrizes para recomendações globais de suplementação de ferro e ácido fólico com o objetivo de melhorar os resultados da gestação e reduzir a anemia materna durante a gravidez.

Essa diretriz mais recente foi atualizada com base em uma revisão sistemática da Cochrane, onde foram avaliados os danos e benefícios da suplementação de ferro e ácido fólico em gestantes saudáveis. Os resultados considerados como evidências fortes para tal recomendação foram à redução do risco de baixo peso no nascimento, anemia materna e deficiência de ferro. 
O programa de suplementação de ferro e ácido fólico ainda faz recomendações adicionais, como integrar o programa com a assistência pré-natal e neonatal que promova ganho adequado de peso gestacional, selecionando todas as mulheres em visitas pré-natal e pós-parto com relação à anemia, para que medidas complementares sejam adotadas (controle de verminoses e promoção da diversidade alimentar e ingestão de combinações alimentícias que melhorem a absorção de ferro) e um sistema de referência para gerenciar casos de anemia grave (OMS, 2013).

No Brasil, foi criado o Programa Nacional de Suplementação de Ferro, pelo Ministério da Saúde, por meio da Portaria MS $\mathrm{n}^{\circ}$ 730, de 13 de maio de 2005, que recomenda a suplementação de $40 \mathrm{mg} /$ dia de ferro elementar (200mg de sulfato ferroso) a partir da $20^{\mathrm{a}}$ semana gestacional e até o terceiro mês pós-parto. Em relação à suplementação de ácido fólico, o Ministério da Saúde recomenda a prescrição de 5mg/dia de ácido fólico de 60 a 90 dias antes da concepção ou durante o primeiro trimestre gestacional (MS, 2013).

Além do programa de suplementação de ferro e ácido fólico, adotado pelo ministério da saúde durante o pré-natal, também é orientado no "Cadernos de Atenção Básica - Atenção ao prénatal de baixo risco" sobre a alimentação da gestante. Consta os "Dez Passos para uma Alimentação Saudável para Gestantes" e também é exemplificado sobre as porções diárias dos grupos de alimentos que devem ser consumidos. Se tratando do consumo de legumes e verduras é sugerido consumir diariamente, pelo menos três porções de legumes e verduras como parte das refeições e três porções ou mais de frutas nas sobremesas e nos lanches. É incentivado também o consumo de arroz e feijão todos os dias, ou pelo menos cinco vezes por semana, orientando a montagem de um prato colorido. E é incentivado evitar o consumo de produtos ultraprocessados (MS, 2013). 
Com base na classificação dos alimentos sugerida pelo guia alimentar brasileiro, consta no guia quatro recomendações para a população em geral, mas que também muito bem se aplica para gestantes, são elas: Faça de alimentos in natura ou minimamente processados a base da sua alimentação; Utilize óleos, gorduras, sal e açúcar em pequenas quantidades ao temperar e cozinhar alimentos e criar preparações culinárias; Limite o uso de alimentos processados, consumindo-os, em pequenas quantidades, como ingredientes de preparações culinárias ou como parte de refeições baseadas em alimentos in natura ou minimamente processados; Evite produtos ultraprocessados. Além dessas recomendações, o guia alimentar ainda sugere uma "regra de ouro": Prefira sempre alimentos in natura ou minimamente processados e preparações culinárias a alimentos ultraprocessados (MS, 2014).

A estratégia de suplementação de ferro e ácido fólico adotada pelo ministério da saúde, associada a um esforço de recomendações vindas de fontes diferentes, mas que convergem para um mesmo objetivo: alimentação saudável durante todas as fases da vida e, inclusive na gestação, visam melhorar a saúde materna e infantil para desfechos gestacionais favoráveis. 


\section{2 - Justificativa}

Dado a importância da alimentação no período gestacional da vida da mulher, para que ela própria alcance suas necessidades nutricionais para manutenção e promoção de sua saúde e também de seu bebê, estudos epidemiológicos são necessários visando conhecimento das condições de saúde e nutrição da mulher nessa importante fase da vida.

KOURY (2010) discorre brevemente acerca dos propósitos que se leva a estudar o estado nutricional da mulher, que predominantemente é realizado durante o período da gestação e pós-parto, com enfoque principalmente nos desfechos relacionados à criança. No presente estudo, destacamos os desfechos relacionados à saúde materna, buscando entender o estado nutricional e o consumo alimentar das gestantes de Cruzeiro do Sul, Acre.

Há escassez de estudos nacionais sobre a saúde e nutrição da gestante, sobretudo na região norte do país. Os poucos estudos se concentram em dois estados da região sudeste, em um estado da região sul e alguns no Nordeste. Há dados na literatura acerca das condições sócio demográficas, ambientais e de saúde na região norte, entretanto, estudos que busquem compreender melhor essa realidade, principalmente sobre o tema abordado, ainda praticamente inexistem nessa região do país.

Desse modo, estudos epidemiológicos sobre condições de saúde e nutrição de gestantes de municípios Amazônicos, oferecem subsídios para planejamento de programas e ações na atenção ao pré-natal e, consequentemente, contribuindo para melhoria das condições de saúde da população materno-infantil. 


\section{3 - Objetivos}

\section{1-Objetivo Geral:}

Investigar a associação entre frequência de consumo de frutas, hortaliças e produtos ultraprocessados, indicadores estado nutricional e sócio demográficos em gestantes de Cruzeiro do Sul, Acre.

\section{2 - Objetivos específicos:}

- Investigar a frequência de consumo de frutas, hortaliças e produtos ultraprocessados das gestantes no segundo trimestre gestacional;

- Avaliar o estado nutricional da gestante no segundo trimestre gestacional em relação a indicadores bioquímicos para anemia, deficiência de vitamina A, ácido fólico e $\beta$-caroteno séricos;

- Investigar a associação entre frequência de consumo de frutas, hortaliças e produtos ultraprocessados segundo estado nutricional e características sócio demográficas das gestantes no segundo trimestre gestacional. 


\section{5 - Métodos}

\section{1 - Área do estudo}

Cruzeiro do Sul é um município situado no interior do estado do Acre, Amazônia Ocidental Brasileira, região Norte do Brasil, ocupando uma área de $8772,9 \mathrm{Km}^{2}$. Conforme o Instituto Brasileiro de Geografia e Estatística (IBGE), o município possui 80.377 habitantes (cerca de 50\% são mulheres), sendo 70,47\% residentes na área urbana (IBGE, 2014). O Índice de Desenvolvimento Humano de Cruzeiro do Sul é de 0,664 (IBGE, 2014), que se compara às cidades como Garanhuns em Pernambuco (IDH 0,664) e Jequié na Bahia (IDH 0,665). Distancia-se $636 \mathrm{Km}$ da capital, Rio Branco, fazendo limite com o Peru, o estado do Amazonas e os municípios acreanos de Tarauacá, Rodrigues Alves, Porto Walter e Mâncio Lima, conforme mostra a Figura 1.

\section{Figura 1. Mapa do Estado do Acre.}

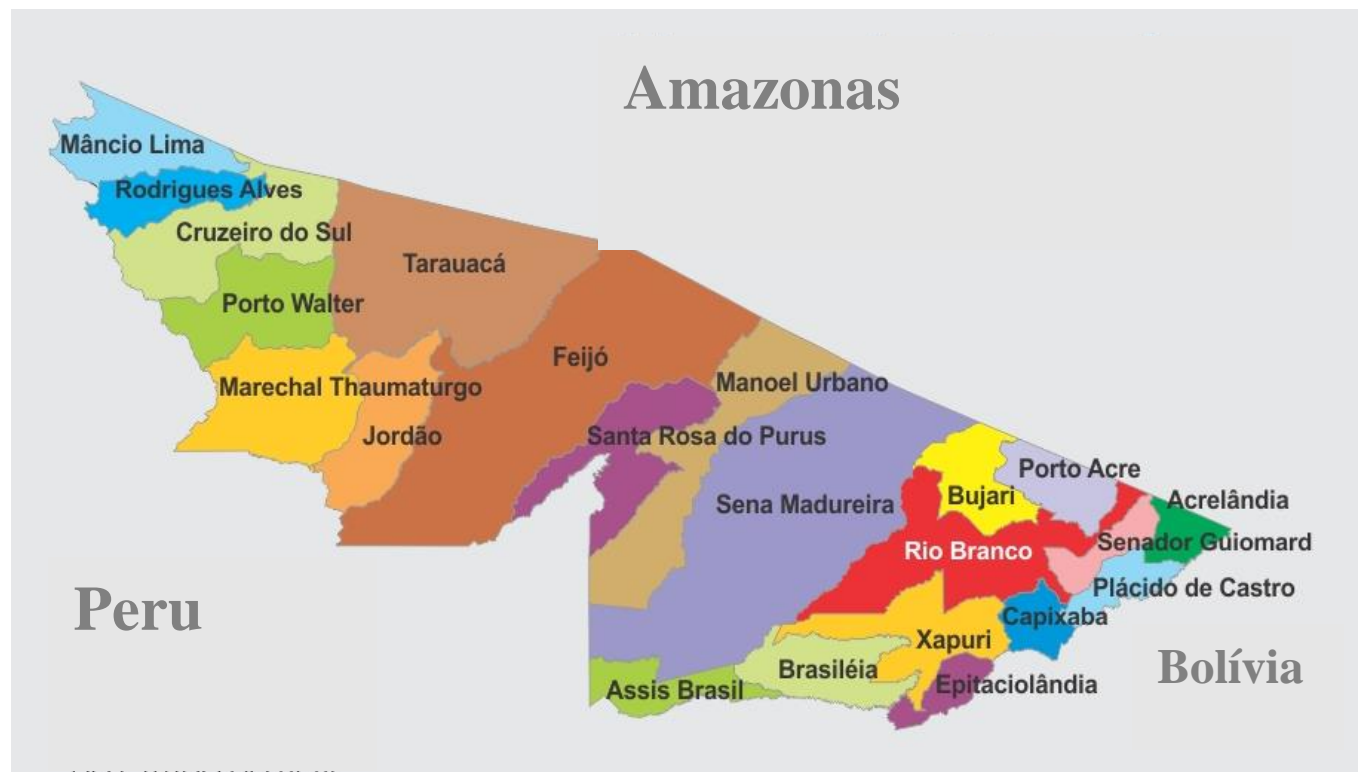

Fonte: modificado de http://grafica.design/acre/ 
No total, 1.783 nascimentos foram registrados em 2013 em Cruzeiro do Sul e $94 \%$ dos partos foram realizados na maternidade do município (MS, 2013). O programa de saúde da família do município tem estimativa de aproximadamente $80 \%$ da população coberta pelas equipes de saúde da família (MS, 2013). O município também apresenta possibilidade de realização de pré-natal na rede privada, contando com cinco médicos que realizam esse trabalho. Porém, ainda assim a população feminina do município é altamente vulnerável, considerando que as chances de parto prematuro são elevadas para mulheres residentes na região Norte $(36 \%$ do total de partos prematuros no Brasil) e que Cruzeiro do Sul apresenta a maior concentração de casos de malária do Acre, sendo responsável por mais de 50\% do total de casos registrados no estado de 2004 a 2008 (COSTA et al., 2010; MIRANDA et al., 2012). Todos os partos assistidos no município são realizados no Hospital da Mulher e da Criança do Juruá, apresentado na Figura 2.

Figura 2. Hospital da mulher e da criança do Juruá, em Cruzeiro do Sul, Acre, 2015.

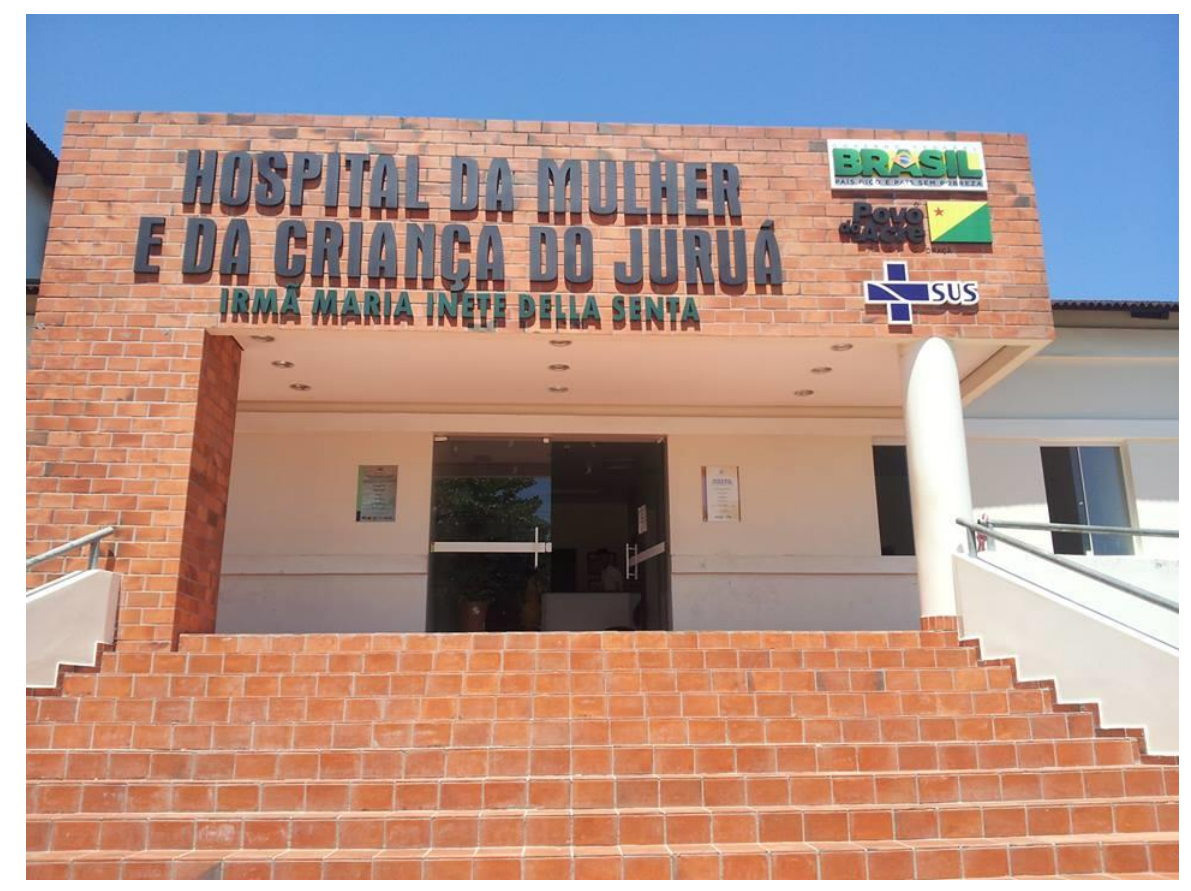

Fonte: http://www.folhadojurua.com.br/wp-content/uploads/2016/02/hospital-maternidade-de-czs.jpg 


\section{2 - Delineamento, população de estudo e aspectos éticos}

O delineamento do estudo principal trata-se de uma coorte de gestantes inscritas no pré-natal da atenção básica à saúde na área urbana da cidade de Cruzeiro do Sul, Acre, de fevereiro de 2015 a janeiro de 2016. De acordo com o número de partos de Cruzeiro do Sul registrados na maternidade do município em 2013, considerando-se $60 \%$ desses partos eram de mulheres residentes na área urbana e uma cobertura das equipes de saúde da família de $80 \%$, esperou-se rastrear cerca de 856 mulheres.

Durante o período citado, foi conduzido um rastreamento semanal para identificação das gestantes inscritas no pré-natal do município por meio de parceria com a Estratégia de Saúde da Família, atualizadas com auxílio das equipes de saúde da atenção básica (20 equipes). As gestantes foram convidadas a participar do projeto e os critérios de inclusão considerados foram: idade gestacional inferior a 20 semanas no momento do rastreamento, ter residência fixa e intenção de realizar o parto no município e aceitar participação na pesquisa. O convite para participar do projeto foi feito pela equipe de pesquisa de campo por telefone, a partir dos dados recebidos através do rastreamento realizado pelos postos de saúde (Anexo 1). A fase de visitas domiciliares para as gestantes que atenderam os critérios de inclusão e aceitaram participar do projeto para aplicação de questionário sócio demográfico e de história de saúde (Anexo 2), ocorreu entre fevereiro de 2015 e janeiro de 2016, momento que as gestantes se encontravam com idade gestacional distintas, sendo a idade gestacional máxima de 20 semanas, que era o limite para serem consideradas elegíveis ao estudo. Após o preenchimento deste questionário, as gestantes eram agendadas para a $1^{\mathrm{a}}$ avaliação clínica, realizada entre $16^{\mathrm{a}}$ e $20^{\mathrm{a}}$ semanas, marcada com base na data da última menstruação. Nessa avaliação, com auxílio de tablets, dados antropométricos, bioquímicos, de consumo alimentar foram coletados juntamente com ultrassonografia obstétrica realizada por médicos da equipe de 
pesquisa, que fornecia os dados que consideramos para a definição da idade gestacional (Anexo 3). Para o presente estudo, utilizaram-se dados para análise transversal sobre consumo alimentar e estado nutricional das gestantes, aferidos na primeira avaliação clínica, com idade gestacional variando de 13 a 25 semanas, de acordo com os dados da ultrassonografia. A Figura 3 demonstra cada etapa realizada para obtenção de dados utilizados no presente estudo.

Figura 3. Etapas realizadas, dados coletados e momento gestacional.

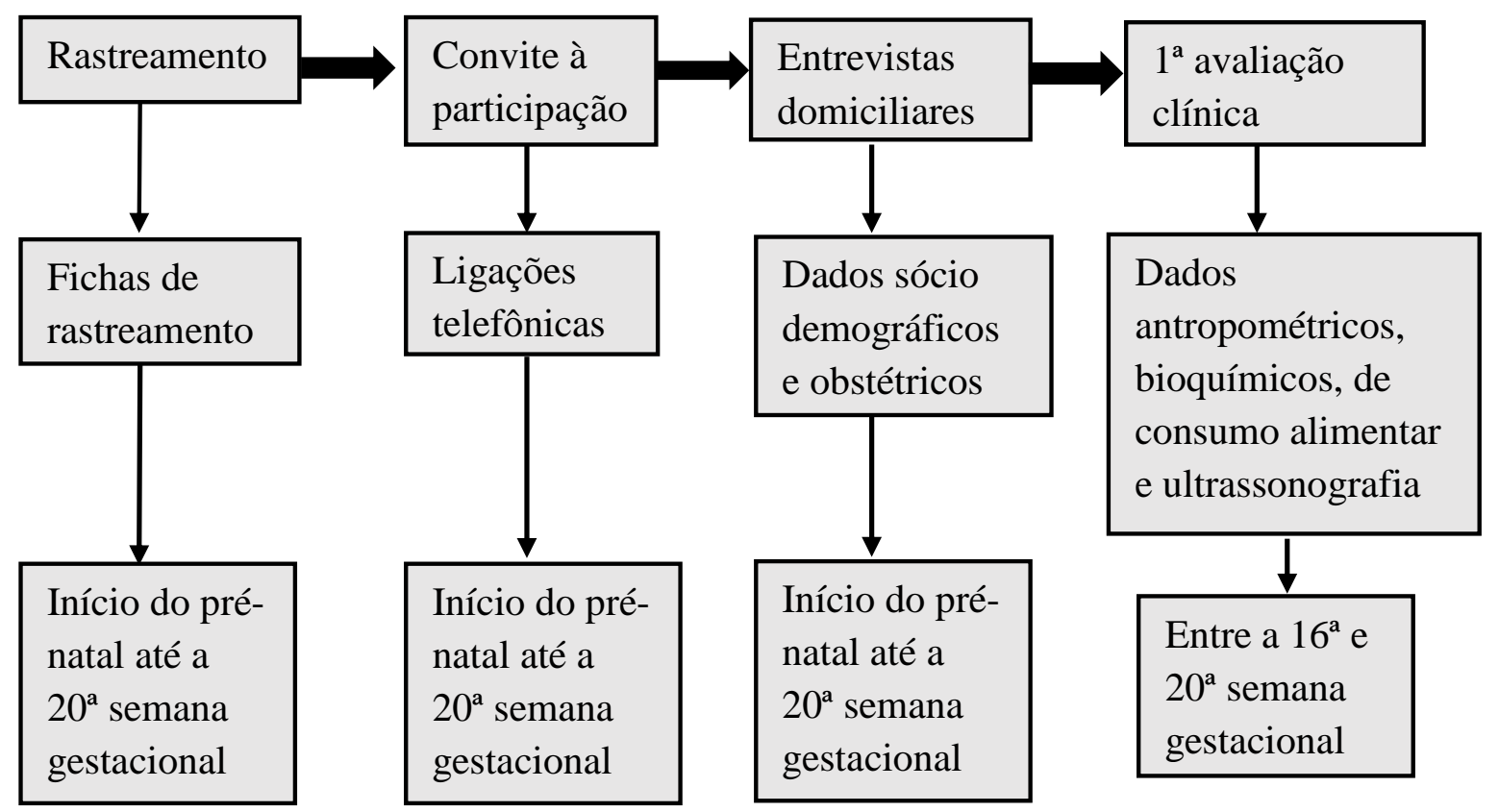

A equipe de trabalho de campo foi composta por entrevistadores (estudantes de graduação de enfermagem e biologia), enfermeiros, médicos, técnicos de laboratório, assistentes de pesquisa (estudantes de pós-graduação em Nutrição em Saúde Pública) e administradores de banco de dados. Toda equipe foi treinada e supervisionada periodicamente no campo pelos assistentes e coordenadores de campo.

A participação no estudo foi voluntária, mediante assinatura do Termo de Consentimento Livre e Esclarecido (Anexo 4), assegurando total sigilo das informações obtidas e a 
apresentação, em momento oportuno, dos resultados individuais da pesquisa. O projeto principal foi aprovado pelo Comitê de Ética em Pesquisa Faculdade de Saúde Pública da Universidade de São Paulo (FSP/USP parecer no 872.613, 13/11/2014). Abaixo, na Figura 4, é apresentado como exemplo um posto de saúde do município, onde era feito rastreamento e também realizadas avaliações clínicas.

Figura 4. Unidade básica de saúde do produtor rural, Cruzeiro do Sul, Acre, 2015.

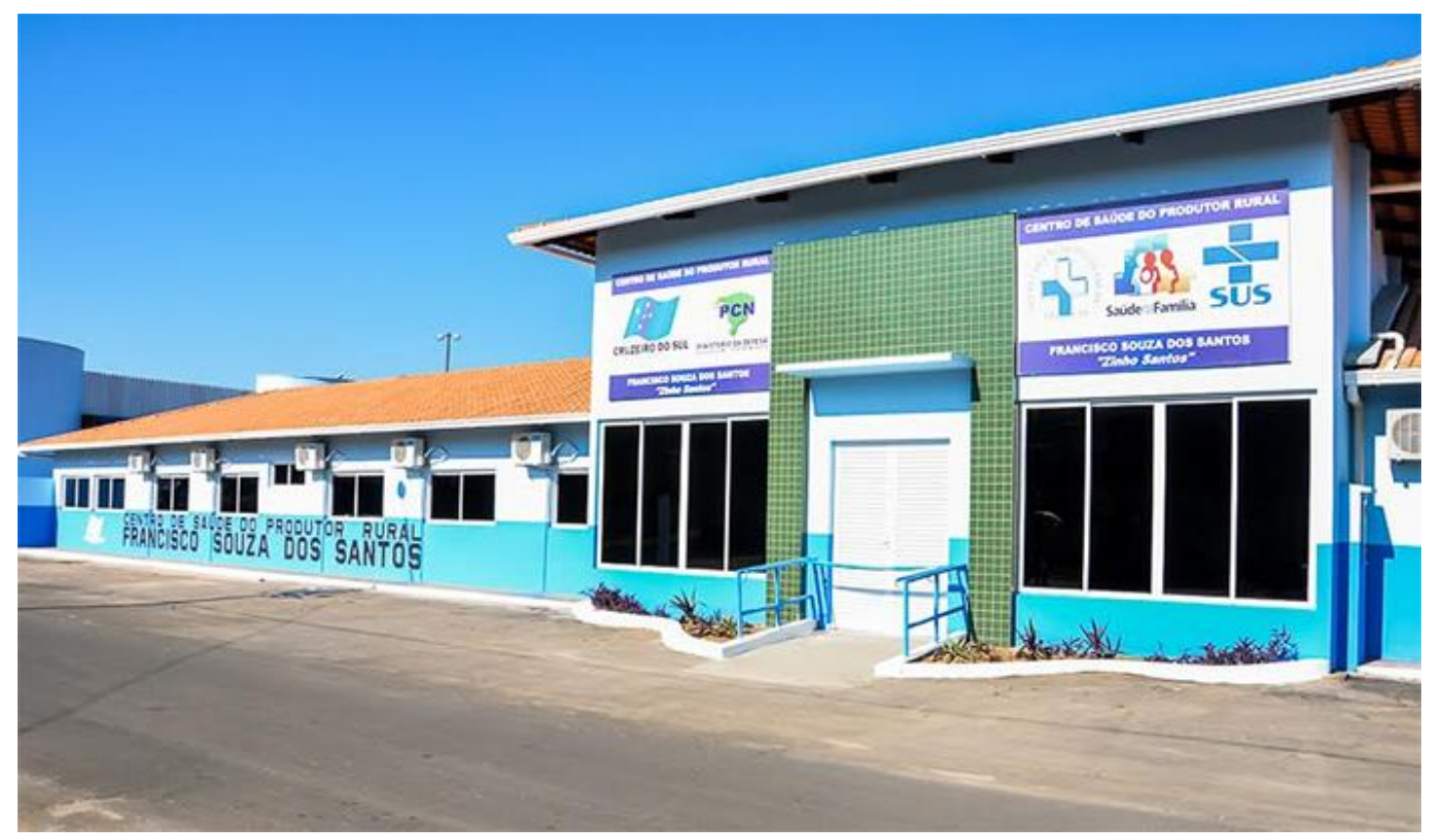

Fonte: http://cdn1.ac24horas.com/wp-content/uploads/2016/04/POSTO_03.jpg

\section{3 - Caracterização das condições sócio demográficas, obstétricas e estilo de vida}

Informações sobre as gestantes participantes do estudo foram obtidas em entrevista pessoal por meio de formulários estruturados para as seguintes variáveis sócio econômicas, demográficas e obstétricas: idade, estado civil, escolaridade, ocupação materna, cor de pele (branca, preta, parda, amarela ou indígena), chefia da família (quem responde como chefe da família: gestante, companheiro ou outra pessoa), recebimento de auxílios governamentais, se 
vive com companheiro/cônjuge, prática de atividade física, tabagismo, consumo de bebida alcoólica e drogas ilícitas, data da última menstruação e número de gestações.

\section{4 - Avaliação antropométrica}

A aferição do peso gestacional foi realizada com o uso de uma balança digital portátil, com capacidade para $150 \mathrm{Kg}$ e variação de $0,1 \mathrm{Kg}$, periodicamente calibrada. Para mensurar a altura, foi utilizado um estadiômetro portátil com precisão de $0,1 \mathrm{~cm}$. Todas as aferições antropométricas seguiram as recomendações da OMS (WHO, 1995), para obtenção do peso e altura, as gestantes se posicionavam de forma ereta no centro do equipamento, sem sapatos, roupas pesadas e objetos no corpo, com os pés devidamente alinhados, braços estendidos ao longo do corpo, com a cabeça erguida, olhando para um ponto fixo na altura dos olhos. Todas as medidas foram obtidas por duplicata e realizadas pela equipe de pesquisa treinada. A avaliação antropométrica pré-gestacional foi realizada por meio do Índice de Massa Corporal, utilizando a seguinte classificação: Baixo peso (IMC $<18,5 \mathrm{~kg} / \mathrm{m}^{2}$ ); Adequado (IMC $\geq 18,5$ $\left.\leq 24,9 \mathrm{~kg} / \mathrm{m}^{2}\right)$; Sobrepeso (IMC $\left.\geq 25,0-\leq 29,9 \mathrm{~kg} / \mathrm{m}^{2}\right)$ e Obesidade $\left(\geq 30 \mathrm{~kg} / \mathrm{m}^{2}\right)(\mathrm{WHO}, 1995)$. O peso pré-gestacional utilizado foi auto referido pelas gestantes no momento da avaliação.

\section{5 - Avaliação do consumo alimentar}

Para avaliação do consumo alimentar, as participantes responderam questões sobre frequência de consumo de grupos de alimentos. O consumo foi avaliado de acordo com cada grupo de alimento (carnes, miúdos, laticínios, feijão, cereais e massas, frutas, frutas regionais, legumes, verduras, industrializados e guloseimas, refrigerantes e bebidas açucaradas), com as seguintes opções de respostas: raramente, 1-3 vezes/mês, 1-3 vezes/semana, 4-6 vezes/semana, 1 vez/dia, 2-3 vezes/dia e $\geq 4$ vezes/dia. Um escore de frequência de consumo de frutas e hortaliças (frutas, legumes e verduras) e alimentos ultraprocessados (industrializados, guloseimas, refrigerantes e bebidas açucaradas) foi construído, conforme descrição em estudo 
anterior para rastreamento de risco para deficiência de micronutrientes em escolares Acreanos (AUGUSTO et al., 2014). Devido ao baixo consumo de verduras e legumes na população, optou-se por agrupá-los em um único grupo denominado "hortaliças". Posteriormente, o consumo de frutas e hortaliças $(\mathrm{FH})$ foi dividido em 3 categorias: baixo consumo (incluindo não consumo e o consumo inferior a 3 vezes/mês), intermediário (1 a 6 vezes/semana) e consumo diário ( $\geq 1 \mathrm{vez} /$ dia). O mesmo procedimento foi adotado para o grupo de produtos industrializados e refrigerantes, denominando esse grupo de "produtos ultraprocessados" (UP).

\section{6 - Avaliação dos parâmetros bioquímicos}

Para coleta de amostras de sangue venoso, as grávidas foram orientadas a fazer jejum prévio de 8 horas. Amostras sanguíneas foram obtidas em dois tubos de ensaio: a) tubo seco (10 mL) para obtenção do soro (envolto por papel alumínio para proteção da luz), mantido em temperatura ambiente para centrifugação em até 1 hora após a coleta; e b) tubo com EDTA (5 ml) para obtenção do plasma, mantido em gelo para centrifugação em até 30 minutos após a coleta. Após centrifugação e separação do plasma e do soro, ambos foram congelados e transportados, em gelo reciclável, para o laboratório de Nutrição Humana do Departamento de Nutrição da FSP/USP onde foram armazenados a $-70^{\circ} \mathrm{C}$, para análises posteriores.

Hemoglobina: Este teste foi realizado no local do trabalho de campo com auxílio de hemoglobinômetro portátil da marca Hemocue. A anemia foi definida quando hemoglobina abaixo de 110,0 g/L (WHO, 2012).

Retinol sérico, $\beta$-caroteno e $\alpha$-tocoferol: O método utilizado para quantificação desses parâmetros foi a Cromatografia Líquida de Alta Performance em fase reversa (HPLC), conforme Gomes et al. (2004). Deficiência de vitamina A foi definida para valores séricos de 
retinol $<0,70 \mu \mathrm{mol} / \mathrm{L}$. Para $\beta$-caroteno e $\alpha$-tocoferol foram observados valores de mediana e intervalo interquartis.

Ácido fólico: A avaliação das concentrações séricas de folato foi realizada por técnica de fluorimunoensaio (CAPPUCCIO et al., 2003). A deficiência foi observada adotando o ponto de corte de $3 \mathrm{ng} / \mathrm{ml}$ (WHO, 2015), e também foi observado o valor mediano e intervalos interquartis.

\section{7 - Análise dos dados}

O desfecho principal de interesse foi o estado nutricional das gestantes, caracterizado pela anemia, deficiência de vitamina A, medianas das concentrações séricas de vitamina E, ácido fólico e $\beta$-caroteno. Em relação ao consumo alimentar, com base na distribuição das frequências de consumo observadas, optou-se por agrupar as categorias de baixo consumo (não consome ou consome mensalmente) com o consumo intermediário (consumo semanal) para comparação com consumo diário, comparando-se com variáveis sócio demográficas e do estado nutricional entre consumidores diários e consumidores não diários de FH e UP.

As variáveis contínuas com distribuição normal foram descritas por meio de média e desvio padrão e quando não apresentavam distribuição normal foram descritivas por meio de medianas e seus respectivos intervalos interquartis. As variáveis categóricas foram descritas por meio de distribuição de frequência simples e IC95\%.

A associação entre variáveis categóricas foi investigada por meio do teste Qui Quadrado de Pearson. As comparações realizadas com variáveis contínuas foram feitas por meio do teste de Mann Whitney, quando não apresentavam distribuição normal, e por meio de análise de variância (ANOVA, para desfechos com distribuição normal). O nível de significância adotado foi $P \leq 0,05$. Todas as análises foram realizadas com auxílio do pacote estatístico STATA 14.0. 


\section{6 - Resultados}

\section{1 - Apresentação das gestantes rastreadas, elegíveis ao estudo e perdas de seguimento}

A figura 5 apresenta o fluxograma para identificação das participantes do estudo. No acompanhamento pré-natal, o rastreamento semanal realizado por enfermeiros e agentes comunitários de saúde ao longo de um ano, entre fevereiro de 2015 e janeiro de 2016 de gestantes na área urbana de Cruzeiro do Sul, identificou o total de 860 gestantes, das quais $588(69 \%)$ atenderam adequadamente os critérios de inclusão do estudo. No rastreamento, foram observados 183 casos não elegíveis (18\% do total, sendo 93 casos incorretamente rastreados pela estimativa de idade gestacional, 52 casos de mudança para outro município ou área rural de Cruzeiro do Sul e 38 abortos ocorridos antes do consentimento à participação), 46 gestantes não encontradas após três tentativas de contato $(5 \%), 41$ recusas à participação (5\%) e 24 casos de contato impossibilitado para convite à participação por informações erroneamente fornecidas na ficha de rastreamento $(3 \%)$.

Após assinatura do termo de consentimento livre e esclarecido e preenchimento da entrevista sócio econômica, apenas uma gestante retirou seu consentimento e assim, 587 entrevistas foram concluídas. As avaliações clínicas foram realizadas entre março de 2015 e março de 2016. No total, 13 gestantes retiraram seu consentimento à participação nessa fase do projeto. As avaliações clínicas foram realizadas majoritariamente aos sábados pela manhã, com 3 procedimentos (coleta de sangue e antropometria, aplicação de questionário e ultrassonografia), o que exigia certa espera e disponibilidade de algumas horas para o projeto, o que impossibilitou a continuação dessas gestantes que retiraram o consentimento. Para a presente análise, considerou-se 506 gestantes que compareceram na primeira avaliação no 
segundo trimestre gestacional e completaram coleta de sangue, avaliação antropométrica e entrevista.

Figura 5. Fluxograma de gestantes rastreadas, elegíveis ao estudo e perdas de seguimento.

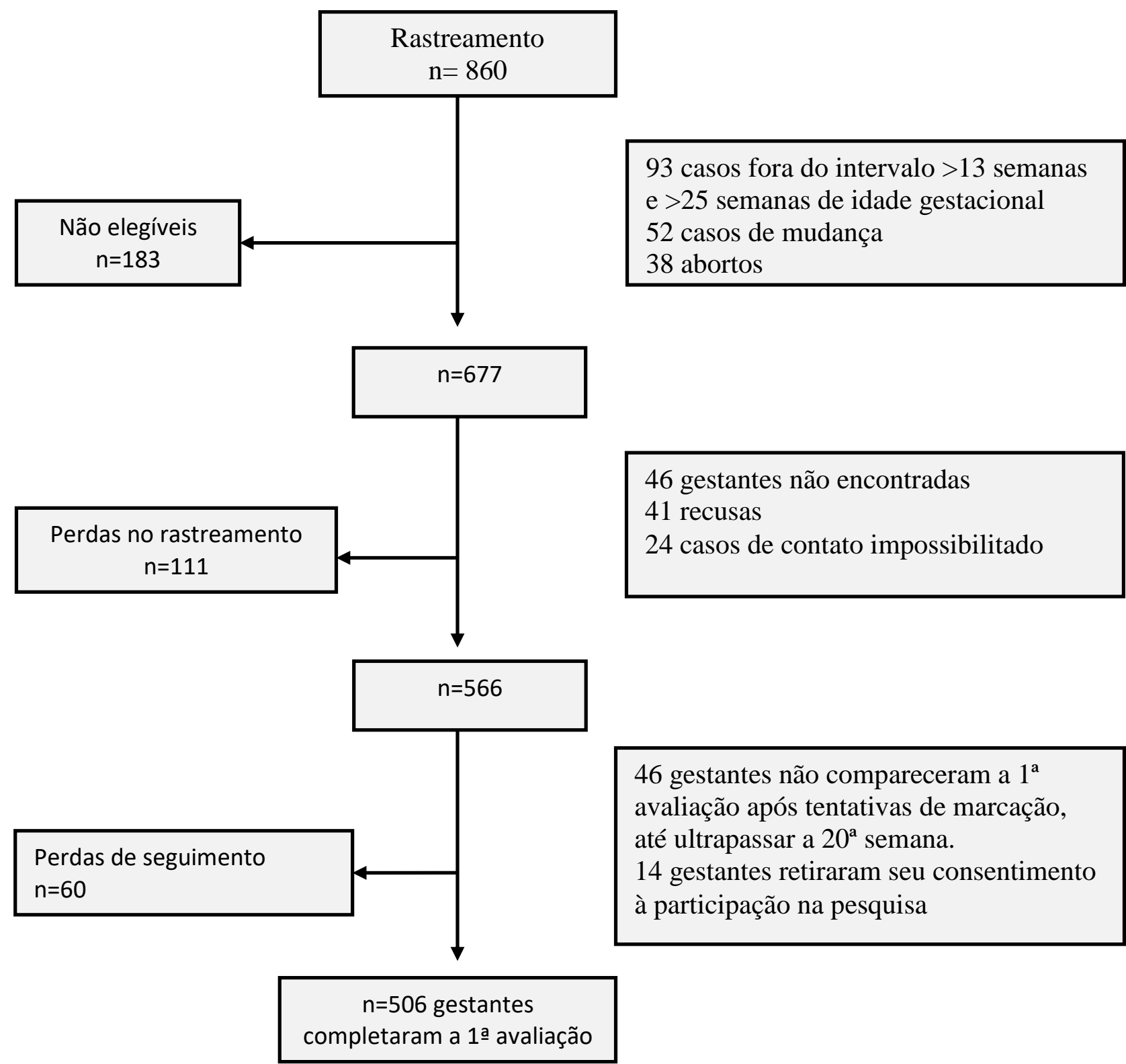

\section{2 - Caracterização das gestantes segundo variáveis socioeconômicas, antropométricas,} pressão arterial e de estilo de vida

A Tabela 1 apresenta a distribuição das gestantes segundo as características sócio demográficas e demográficas. Observamos uma porcentagem considerável de gestantes 
adolescentes que fizeram parte do estudo (26\%) e em torno de $8 \%$ das gestantes tinham 35 anos ou mais. A idade mínima entre as gestantes estudadas foi de 13 anos e a idade máxima de 40 anos (dados não apresentados). A maioria se identificou como sendo de cor parda. A frequência de primigestas correspondeu a quase metade da amostra $(43,5 \%)$ e mais da metade $(55,3 \%)$ das mulheres não exerce trabalho remunerado.

Tabela 1. Características das gestantes segundo variáveis sócio demográficas e paridade. Cruzeiro do Sul, Acre, 2015 (N= 506).

\begin{tabular}{lll}
\hline \multicolumn{1}{c}{ Variáveis } & n & $\%$ \\
\hline Idade (anos) & 130 & 25,7 \\
$<20$ & 153 & 30,2 \\
$20-24$ & 107 & 21,1 \\
$25-29$ & 117 & 22,9 \\
$\geq 30$ & & \\
Escolaridade & 143 & 28,3 \\
$\leq 9$ anos & 277 & 54,7 \\
$10-12$ anos & 67 & 13,2 \\
$>12$ anos & & \\
Cor da Pele & 4 & 0,8 \\
Indígena & 18 & 3,6 \\
Amarela & 25 & 4,9 \\
Preta & 76 & 15,0 \\
Branco & 383 & 75,7 \\
Parda & & \\
Situação conjugal & 394 & 77,9 \\
Vive com o companheiro & & \\
Recebe Bolsa Família & 196 & 38,7 \\
Sim & & \\
Número de filhos & 220 & 43,5 \\
Primigesta & 197 & 38,9 \\
1 a 2 fillhos & 89 & 17,6 \\
3 ou mais filhos & & \\
Exerce trabalho remunerado & 280 & 55,3 \\
Não & & \\
Gestante chefe do domicílio & 432 & 85,4 \\
Não & & \\
\hline
\end{tabular}


A Tabela 2 descreve as características antropométricas e de pressão arterial das participantes do estudo. No total, $30,7 \%$ das gestantes referiram peso pré-gestacional acima do peso adequado.

Tabela 2. Características antropométricas (IMC, índice de massa corporal) e pressão arterial de gestantes inscritas o pré-natal da atenção básica de Cruzeiro do Sul, Acre, $2015(\mathrm{~N}=506)$.

\begin{tabular}{lll}
\hline \multicolumn{1}{c}{ Variáveis } & $\mathbf{n}$ & $\%$ \\
\hline IMC pré-gestacional $\left(\mathbf{k g} / \mathbf{m}^{\mathbf{2}}\right)$ & 51 & 10,1 \\
Baixo peso $(<18,5)$ & 299 & 59,2 \\
Adequado $(\geq 18,5-\leq 24,9)$ & 120 & 23,8 \\
Sobrepeso $(\geq 25,0-\leq 29,9)$ & 35 & 6,93 \\
Obesidade $(\geq 30)$ & 1 & 0,2 \\
Sem informação & & \\
Pressão Arterial $(\mathbf{m m H g}) * *$ & & \\
Sistólica & 488 & 96,4 \\
Normal & 17 & 3,4 \\
Limítrofe & 1 & 0,2 \\
Hipertensão arterial leve & \multicolumn{2}{c}{} \\
Diastólica & 502 & 99,2 \\
Normal & 4 & 0,8 \\
Limítrofe & **Critérios de classificação: pressão arterial sistólica normal (<130), limítrofe (130- 139), elevada \\
( $\geq 140$ - $\leq 159) ;$ pressão arterial diastólica normal (<85) e limítrofe (85-89).
\end{tabular}

De acordo com as características de estilo de vida apresentadas na Tabela 3, poucas gestantes referiram manter tabagismo $(4 \%)$ e consumo de bebidas alcóolicas $(0,6 \%)$ na gravidez. A prática de atividade física no lazer foi reportada por somente $17 \%$ das gestantes; destas, somente 4,5\% relatou realizar 150 minutos ou mais de prática de caminhada no lazer por semana. A proporção de gestantes que referiu não consumir nenhum suplemento vitamínico ou mineral no segundo trimestre gestacional foi consideravelmente alta $(42,5 \%)$. Para o 
consumo de drogas ilícitas, apenas 2 gestantes referiram ter feito o uso dessas substâncias até aquele momento da gestação (dados não apresentados).

Tabela 3 - Características de estilo de vida de gestantes inscritas no pré-natal da atenção básica de Cruzeiro do Sul, Acre, 2015 (N=506).

\begin{tabular}{lll}
\hline \multicolumn{1}{c}{ Variáveis } & n & \% \\
\hline Tabagismo durante a gestação & & \\
Não & 486 & 96,0 \\
Sim & 20 & 3,9 \\
Consumo de bebidas alcóolicas nos últimos 3 meses & & \\
Não & 465 & 91,9 \\
Sim, uma ou duas vezes & 33 & 6,5 \\
Sim, mensalmente & 5 & 0,9 \\
Sim, semanalmente & 3 & 0,6 \\
Prática de caminhada no lazer & & \\
Não & 420 & 83,0 \\
Sim & 86 & 17,0 \\
Uso de suplementos & & \\
Não & 215 & 42,5 \\
Sim & 291 & 57,5 \\
\hline
\end{tabular}

\section{3 - Indicadores bioquímicos do estado nutricional das gestantes estudadas}

A Tabela 4 apresenta dados descritivos dos indicadores bioquímicos analisados. As prevalências de anemia e de deficiência de vitamina A corresponderam a 15,4\% e 10,9\%, respectivamente, sendo consideradas problema moderado de saúde pública nesta população. Em contraste, as concentrações séricas de ácido fólico apresentaram-se elevadas em toda população de estudo, observando-se apenas 2 gestantes com valores menores que $3 \mathrm{ng} / \mathrm{ml}$ (indicador de deficiência de ácido fólico em mulheres em idade reprodutiva segundo publicação técnica da OMS 2015). 
Tabela 4. Indicadores bioquímicos do estado nutricional de gestantes no segundo trimestre gestacional inscritas no pré-natal da atenção básica de saúde de Cruzeiro do Sul, Acre, 2015 (n=496).

\begin{tabular}{|c|c|c|}
\hline Variáveis & Valo & escritivos \\
\hline Anemia (\%, IC95\%) & 15,4 & $(12,3 ; 18,9)$ \\
\hline Deficiência de vitamina A (\%, IC95\%) & 10,9 & $(8,3 ; 14,0)$ \\
\hline Hemoglobina, $m g / d L$ (média, $D P$ ) & 12,1 & $(1,3)$ \\
\hline Ácido Fólico, $n g / m L$, (mediana, $I Q_{25-75}$ ) & 12,2 & $(8,7 ; 18,0)$ \\
\hline Vitamina A, $\mu \mathrm{mol} / \mathrm{L}$ (mediana, $\left.I Q_{25-75}\right)$ & 1,8 & $(1,0 ; 2,6)$ \\
\hline Beta caroteno, $\mathrm{nmol} / \mathrm{L}$ (mediana, $I Q_{25-75}$ ) & 0,4 & $(0,2 ; 0,8)$ \\
\hline Vitamina E, $\mu \mathrm{mol} / \mathrm{L}$ (mediana, $\left.I Q_{25-75}\right)$ & 21,0 & $(15,5 ; 28,9)$ \\
\hline
\end{tabular}

6.4 - Associação entre características sócio demográficas e antropométricas das gestantes, segundo deficiência de vitamina $A$ (DVA), anemia e valores de folato, $\beta$-caroteno $e$ vitamina E séricas abaixo da mediana

As Tabelas 5 e 6 apresentam as características sócio demográficas e antropométricas segundo indicadores bioquímicos do estado nutricional no segundo trimestre gestacional. A deficiência de vitamina A foi positivamente associada à idade abaixo de 20 anos, ser primigesta e possuir menores de IMC pré- valores medianos gestacional (Tabela 5). Em relação à prevalência de anemia, ser adolescente (idade abaixo de 20 anos), menos de 10 anos de escolaridade e apresentar menores valores medianos de IMC pré-gestacional foram associados ao risco para anemia (Tabela 5). Para as concentrações séricas de $\beta$-caroteno, novamente, idade menor que 20 anos, escolaridade menor que 10 anos e receber bolsa família foram associados a menores valores para esse parâmetro (Tabela 6). Da mesma forma, para as concentrações séricas de folato, as mesmas variáveis (idade menor que 20 anos, escolaridade menor que 10 anos e 
receber bolsa família) foram também associadas a valores abaixo da mediana de folato $(12,3$ ng/mL). Em relação à concentração sérica de vitamina $\mathrm{E}$, além da associação negativa com as variáveis idade menor que 20 anos, menor escolaridade e menor IMC pré-gestacional, observou-se associação positiva com o fato da gestante não ser chefe da família (Tabela 6).

Tabela 5 - Características sócio demográficas e antropométricas das gestantes inscritas no pré-natal da atenção básica segundo deficiência de vitamina A (DVA) e anemia. Cruzeiro do Sul, Acre, 2015 (n=496).

\begin{tabular}{|c|c|c|c|c|}
\hline $\begin{array}{l}\text { Características sócio } \\
\text { demográficas e } \\
\text { antropométricas }\end{array}$ & $\begin{array}{l}\text { DVA } \\
\text { n }(\%)\end{array}$ & $P$ & $\begin{array}{l}\text { Anemia } \\
\text { n }(\%)\end{array}$ & $\boldsymbol{P}$ \\
\hline \multicolumn{5}{|l|}{ Idade } \\
\hline$<20$ & $20(16,0)$ & & $26(21,3)$ & \\
\hline$\geq 20$ & $34(9,2)$ & $\mathbf{0 , 0 3 4}$ & $50(13,5)$ & $\mathbf{0 , 0 3 8}$ \\
\hline \multicolumn{5}{|l|}{ Escolaridade } \\
\hline$<10$ anos & $20(14,5)$ & & $29(21,3)$ & \\
\hline$\geq 10$ anos & $32(9,4)$ & 0,108 & $46(13,6)$ & $\mathbf{0 , 0 3 7}$ \\
\hline \multicolumn{5}{|l|}{ Cor da pele } \\
\hline Não-branco & $46(10,9)$ & & $69(16,4)$ & \\
\hline Branco & $8(10,7)$ & 0,947 & $7(9,7)$ & 0,148 \\
\hline \multicolumn{5}{|l|}{ Situação conjugal } \\
\hline Com companheiro & $43(11,2)$ & & $57(14,8)$ & \\
\hline Sem companheiro & $11(9,9)$ & 0,708 & $19(17,6)$ & 0,478 \\
\hline \multicolumn{5}{|l|}{ Bolsa Família } \\
\hline Não & $32(10,5)$ & & $43(14,1)$ & \\
\hline Sim & $22(11,5)$ & 0,745 & $33(17,5)$ & 0,322 \\
\hline \multicolumn{5}{|l|}{ Primípara } \\
\hline Sim & $30(14,1)$ & & $36(17,3)$ & \\
\hline Não & $24(8,5)$ & 0,047 & $40(14,1)$ & 0,340 \\
\hline \multicolumn{5}{|l|}{ Trabalho remunerado } \\
\hline Não & $34(12,4)$ & & $41(15,1)$ & \\
\hline $\operatorname{Sim}$ & $20(8,8)$ & 0,215 & $35(15,8)$ & 0,815 \\
\hline \multicolumn{5}{|l|}{ Chefe de família } \\
\hline Não & $49(11,6)$ & & $65(15,5)$ & \\
\hline $\operatorname{Sim}$ & $5(6,8)$ & 0,216 & $11(15,1)$ & 0,929 \\
\hline $\begin{array}{l}\text { IMC pré-gestacional } \\
\text { (mediana, IQ25-75) }\end{array}$ & $21,6(19,1 ; 23,3)$ & $\mathbf{0 , 0 0 3}$ & $21,2(18,9 ; 24,5)$ & $\mathbf{0 , 0 0 3}$ \\
\hline
\end{tabular}


Tabela 6 - Características sócio demográficas e antropométricas das gestantes inscritas no pré-natal da atenção básica, segundo concentrações séricas de folato, $\beta$-caroteno e vitamina E séricas abaixo da mediana. Cruzeiro do Sul, Acre, 2015 (n=495).

\begin{tabular}{|c|c|c|c|c|c|c|}
\hline $\begin{array}{l}\text { Características } \\
\text { sócio } \\
\text { demográficas e } \\
\text { antropométricas }\end{array}$ & $\begin{array}{c}\text { Folato } \\
\text { (abaixo da } \\
\text { mediana) } \\
\text { n }(\%)\end{array}$ & $P$ & $\begin{array}{c}\text { B-caroteno } \\
\text { (abaixo da } \\
\text { mediana) } \\
\text { n }(\%)\end{array}$ & $P$ & $\begin{array}{l}\text { Vitamina E } \\
\text { (abaixo da } \\
\text { mediana) } \\
\text { n }(\%)\end{array}$ & $P$ \\
\hline \multicolumn{7}{|l|}{ Idade } \\
\hline$<20$ & $72(57,6)$ & & $73(58,4)$ & & $78(62,4)$ & \\
\hline$>=20$ & $174(47,4)$ & 0,049 & $172(46,5)$ & $\mathbf{0 , 0 2 1}$ & $170(45,8)$ & 0,001 \\
\hline \multicolumn{7}{|l|}{ Escolaridade } \\
\hline$<10$ anos & $78(56,5)$ & & $85(61,6)$ & & $88(63,8)$ & \\
\hline$\geq 10$ anos & $155(46,3)$ & $\mathbf{0 , 0 4 3}$ & $153(45,3)$ & 0,001 & $149(43,9)$ & $\mathbf{0 , 0 0 0}$ \\
\hline \multicolumn{7}{|l|}{ Cor da pele } \\
\hline Não-branco & $214(51,2)$ & & $208(49,5)$ & & $216(51,3)$ & \\
\hline Branco & $32(43,2)$ & 0,207 & $37(49,3)$ & 0,976 & $32(42,7)$ & 0,168 \\
\hline \multicolumn{7}{|l|}{ Situação conjugal } \\
\hline Com companheiro & $189(49,3)$ & & $189(49,2)$ & & $191(49,6)$ & \\
\hline Sem companheiro & $57(52,3)$ & 0,587 & $56(50,4)$ & 0,819 & $57(51,3)$ & 0,747 \\
\hline \multicolumn{7}{|l|}{ Bolsa Família } \\
\hline Não & $134(44,7)$ & & $137(45,2)$ & & $144(47,4)$ & \\
\hline Sim & $112(58,3)$ & $\mathbf{0 , 0 0 3}$ & $108(56,2)$ & $\mathbf{0 , 0 1 7}$ & $104(54,2)$ & 0,140 \\
\hline \multicolumn{7}{|l|}{ Primigesta } \\
\hline Sim & $103(48,7)$ & & $104(48,8)$ & & $109(51,2)$ & \\
\hline Não & $143(51,2)$ & 0,524 & $141(50,0)$ & 0,796 & $139(49,1)$ & 0,650 \\
\hline \multicolumn{7}{|l|}{$\begin{array}{l}\text { Trabalho } \\
\text { remunerado }\end{array}$} \\
\hline Não & $146(53,7)$ & & $142(52,2)$ & & $143(52,4)$ & \\
\hline Sim & $100(45,4)$ & 0,070 & $103(46,2)$ & 0,183 & $105(47,1)$ & 0,241 \\
\hline \multicolumn{7}{|l|}{ Chefe de família } \\
\hline Não & $210(50,0)$ & & $213(50,6)$ & & $219(51,9)$ & \\
\hline Sim & $36(50,0)$ & 1,000 & $32(43,2)$ & 0,243 & $29(39,2)$ & $\mathbf{0 , 0 4 4}$ \\
\hline
\end{tabular}

IMC prégestacional (para comparação entre duas variáveis contínuas independentes). Valores medianos das concentrações séricas: Folato $=12,25 \mathrm{ng} / \mathrm{mL}, \beta$-caroteno $=0,45 \mu \mathrm{mol} / \mathrm{L}$ e vitamina $E=21,05 \mu \mathrm{mol} / \mathrm{L} . \mathrm{IMC}: \mathrm{Kg} / \mathrm{m}^{2}$ 
6.5 - Associação entre frequência de consumo diário de frutas e hortaliças $(\mathrm{FH})$ e produtos ultraprocessados (UP), características sócio demográficas e concentração de hemoglobina sanguínea e vitaminas séricas

A frequência de consumo diário de frutas e hortaliças e produtos ultraprocessados segundo características sócio demográficas são apresentadas na Tabela 7. Maior escolaridade foi associada a maior proporção de gestantes com consumo diário de frutas e hortaliças. Gestantes adolescentes $(<20$ anos) e primigestas foram associadas a maior proporção de gestantes com consumo diário de produtos ultraprocessados. Do total, 31,62\% das gestantes consumiam refrigerantes e bebidas açucaradas e $21,95 \%$ consumiam produtos industrializados e guloseimas, pelo menos uma vez por dia (dados não apresentados).

Vale ressaltar também alguns dados descritivos a respeito do consumo de frutas, hortaliças e alimentos ultraprocessados das gestantes estudadas. Número expressivo de gestantes (60\%) não consumia frutas e hortaliças ao menos uma vez por dia. E $13 \%$ do total, relatou consumir alimentos ultraprocessados diariamente (dados não apresentados).

A Tabela 8 apresenta os resultados da associação entre frequência de consumo diário de frutas e hortaliças e de produtos ultraprocessados e concentração de hemoglobina sanguínea e vitaminas séricas nas gestantes no segundo trimestre gestacional. Houve associação entre consumo diário de frutas e hortaliças e maiores valores medianos para concentração sérica de $\beta$-caroteno e vitamina A. Não houve associação entre frequência de consumo diário de produtos ultraprocessados e os parâmetros bioquímicos analisados. 
Tabela 7 - Associação entre frequência de consumo diário de frutas e hortaliças (FH) e produtos ultraprocessados (UP) e características sócio demográficas das gestantes inscritas no pré-natal da atenção básica. Cruzeiro do Sul, Acre, 2015. (n=506).

\begin{tabular}{|c|c|c|c|c|c|c|}
\hline \multirow[t]{2}{*}{$\begin{array}{l}\text { Características } \\
\text { sócio demográficas }\end{array}$} & \multicolumn{2}{|c|}{$\begin{array}{c}\text { Consumo diário de } \mathbf{F H} \\
\mathbf{N}(\%)\end{array}$} & \multicolumn{4}{|c|}{ Consumo diário de UP } \\
\hline & Não & Sim & $\boldsymbol{P}$ & Não & Sim & $P$ \\
\hline \multicolumn{7}{|l|}{ Idade } \\
\hline$<20$ & $82(63,1)$ & $48(36,9)$ & & $104(80,0)$ & $26(20,0)$ & \\
\hline$\geq 20$ & $221(58,8)$ & $155(41,2)$ & 0,389 & $336(89,4)$ & $40(10,6)$ & 0,006 \\
\hline \multicolumn{7}{|l|}{ Escolaridade } \\
\hline$<10$ anos & $96(67,1)$ & $47(32,9)$ & & $126(88,1)$ & $17(11,9)$ & \\
\hline$\geq 10$ & $198(57,6)$ & $146(42,4)$ & 0,049 & $297(86,9)$ & $47(13,7)$ & 0,598 \\
\hline \multicolumn{7}{|l|}{ Cor da pele } \\
\hline Não-branco & $262(60,9)$ & $168(39,07)$ & & $370(86,0)$ & $60(13,9)$ & \\
\hline Branco & $41(53,95)$ & $35(46,0)$ & 0,252 & $70(92,1)$ & $6(7,9)$ & 0,148 \\
\hline \multicolumn{7}{|l|}{ Situação conjugal } \\
\hline Com companheiro & $231(58,6)$ & $163(41,4)$ & & $346(87,8)$ & $48(12,2)$ & \\
\hline Sem companheiro & $72(64,3)$ & $40(35,7)$ & 0,281 & $94(83,9)$ & $18(16,1)$ & 0,281 \\
\hline \multicolumn{7}{|l|}{ Bolsa Família } \\
\hline Não & $183(59,0)$ & $127(41,0)$ & & $277(89,3)$ & $33(10,6)$ & \\
\hline $\operatorname{Sim}$ & $120(61,2)$ & $76(38,8)$ & 0,624 & $163(83,2)$ & $33(16,8)$ & 0,044 \\
\hline \multicolumn{7}{|l|}{ Primigesta } \\
\hline Não & $165(57,7)$ & $121(42,3)$ & & $259(90,6)$ & $27(9,4)$ & \\
\hline Sim & $138(62,7)$ & $82(37,3)$ & 0,252 & $181(82,3)$ & $39(17,7)$ & 0,006 \\
\hline \multicolumn{7}{|l|}{$\begin{array}{l}\text { Trabalho } \\
\text { remunerado }\end{array}$} \\
\hline Não & $166(59,3)$ & $114(40,7)$ & & $238(85,0)$ & $42(15,0)$ & \\
\hline Sim & $137(60,6)$ & $89(39,4)$ & 0,761 & $202(89,38)$ & $24(10,6)$ & 0,146 \\
\hline \multicolumn{7}{|l|}{ Chefe de família } \\
\hline Não & $260(60,2)$ & $172(39,8)$ & & $371(85,9)$ & $61(14,1)$ & \\
\hline Sim & $43(58,9)$ & $31(41,9)$ & 0,736 & $69(93,2)$ & $5(6,8)$ & 0,082 \\
\hline
\end{tabular}


Tabela 8 - Associação entre frequência de consumo diário de frutas e hortaliças (FH) e produtos ultraprocessados (UP) e concentração de hemoglobina sanguínea e vitaminas séricas em gestantes inscritas no pré-natal da atenção básica de Cruzeiro do Sul, Acre, $2015(n=496)$.

\begin{tabular}{|c|c|c|c|c|c|c|}
\hline \multirow{2}{*}{$\begin{array}{l}\text { Parâmetros } \\
\text { Bioquímicos } \\
\text { (mediana, IIQ) }\end{array}$} & \multicolumn{2}{|c|}{ Consumo diário de FH } & \multicolumn{4}{|c|}{ Consumo diário de UP } \\
\hline & Sim & Não & $\boldsymbol{P}$ & Sim & Não & $\boldsymbol{P}$ \\
\hline $\begin{array}{l}\boldsymbol{\beta} \text {-caroteno } \\
(\mu \mathrm{mol} / \mathrm{L})\end{array}$ & $0,5(0,3-0,8)$ & $0,4(0,2-0,8)$ & 0,024 & $0,4(0,3-0,6)$ & $0,5(0,2-0,8)$ & 0,079 \\
\hline $\begin{array}{l}\text { Vitamina E } \\
(\mu \mathrm{mol} / \mathrm{L})\end{array}$ & $21,9(16,4-30,5)$ & $20,6(14,8-28,4)$ & 0,137 & $19,9(15,5-28,9)$ & $21,4(15,5-28,9)$ & 0,643 \\
\hline $\begin{array}{l}\text { Vitamina A } \\
(\mu \mathrm{mol} / \mathrm{L})\end{array}$ & $1,9(1,1-2,7)$ & $1,7(1,0-2,5)$ & 0,034 & $1,7(1,2-2,2)$ & $1,8(1,0-2,7)$ & 0,611 \\
\hline $\begin{array}{l}\text { Ácido fólico } \\
(n g / m L)\end{array}$ & $12,5(9,3-18,2)$ & $12,1(8,4-17,7)$ & 0,166 & $10,2(7,3-17,2)$ & $12,6(8,9-18,2)$ & 0,092 \\
\hline $\begin{array}{l}\text { Hemoglobina } \\
(\mathrm{mg} / \mathrm{dL})\end{array}$ & $12,1(11,5-12,9)$ & $12,2(11,3-12,9)$ & 0,741 & $12,1(11,3-12,6)$ & $12,2(11,4-12,9)$ & 0,342 \\
\hline
\end{tabular}




\section{7 - Discussão}

No presente estudo, características sócio demográficas foram associadas ao estado nutricional no segundo trimestre gestacional em mulheres inscritas no pré-natal da atenção básica à saúde em um município do interior do Acre, Amazônia Ocidental Brasileira. Anemia e deficiência de vitamina A foram observadas em 15,4\% e 10,9\% das gestantes estudadas, respectivamente. Concentrações séricas abaixo das medianas de $\beta$-caroteno, vitamina $\mathrm{E}$ e folato foram associadas à menor idade $(<20$ anos $)$, menor escolaridade $(<10$ anos $)$, ser beneficiária do programa bolsa família e ser chefe de família. Anemia e deficiência de vitamina A foram também associadas à menor idade, menor escolaridade e menor IMC pré-gestacional. Gestantes com consumo diário de frutas e hortaliças apresentaram maiores concentrações séricas de $\beta$-caroteno e vitamina $\mathrm{A}$ quando comparadas às gestantes sem consumo diário desses alimentos. Não houve associação entre consumo de produtos ultraprocessados e os indicadores bioquímicos avaliados.

O perfil sócio demográfico das gestantes estudadas foi semelhante ao observado em outros estudos realizados nas regiões Sul e Sudeste do país. Cerca de um quarto das participantes do nosso estudo eram adolescentes. Situação semelhante (28\%) foi encontrada no município de Viamão, área metropolitana de Porto Alegre, Rio Grande do Sul, onde foram recrutadas gestantes de unidades básicas de saúde ao longo de um ano e quatro meses para um estudo caso-controle (VÍTOLO et al., 2011).

O nível de escolaridade das gestantes do presente estudo também foi semelhante ao observado em estudo anterior realizado em unidades básicas de saúde, em uma cidade do interior do estado de São Paulo, onde 21,05\% das gestantes tinham menos de 8 anos de escolaridade (CARVALHÃES et al., 2013). A situação da frequência de trabalho remunerado em nosso estudo, também foi próxima ao resultado encontrado em estudos realizados em unidades básicas das cidades de Botucatu, São Paulo e Queimados, Rio de Janeiro. Mais da metade das 
gestantes participantes desses estudos não exerciam trabalho remunerado ou não trabalhavam fora de casa (CARVALHÃES et al., 2013; Coelho et al., 2015).

Em relação ao estado nutricional pré-gestacional das gestantes do presente estudo, 31\% iniciaram a gestação com sobrepeso ou obesidade. Resultados semelhantes foram encontrados em estudos realizados nos municípios de Viamão e em Botucatu: 28\% e 34\% das gestantes, respectivamente, apresentaram excesso de peso no início da gestação (VÍTOLO et al., 2011; CARVALHÃES et al., 2013). O IMC pré-gestacional tem sido associado a desfechos adversos na gravidez. Estudo recente, conduzido com mais de 90 mil mulheres japonesas observou que mulheres com valores maiores de IMC pré-gestacional apresentavam de duas a três vezes mais chances de desenvolver hipertensão induzida pela gestação, de duas a seis vezes mais chances de desenvolver diabetes gestacional, de duas a quatro vezes mais chances de ter um bebê macrossômico, até duas vezes e meia mais chances de parto cesariana e também de ter hemorragia no pós-parto cesariana (ENOMOTO et al., 2016).

Outro fator importante relacionado ao estado nutricional gestacional é a prática de atividade física habitual. Em nosso estudo, apenas $17 \%$ das gestantes relataram praticar caminhada no lazer; destas, poucas referiram alcançar pelo menos 150 minutos semanais de caminhada valores abaixo desse ponto de corte é utilizado pela OMS para classificação de inatividade física (WHO, 2002). O tipo de atividade física na gestação, frequência e duração ainda é palco de muita discussão na literatura. Entretanto, alguns autores recomendam a prática regular de atividade física na gravidez, dependendo do condicionamento pré-gestacional da mulher e com acompanhamento, pois sugerem que pode ser um estímulo para mudança no estilo de vida, com efeitos positivos na saúde da mulher (ARTAL E O’TOOLE, 2003).

Em relação à ocorrência da anemia na gravidez, são ainda escassos estudos representativos em gestantes brasileiras para estimativas mais precisas da prevalência de anemia em nível nacional ou por regiões. A OMS estima que em países desenvolvidos a prevalência de anemia 
entre gestantes seja de $23 \%$ e em países em desenvolvimento seja de 52\% (WHO, 2001). No Brasil, alguns estudos transversais em amostras pequenas encontraram prevalências entre 16 e 50\%, dependendo da região, idade gestacional e nível sócio econômico (VÍTOLO et al., 2006; FERREIRA et al., 2008; ARAÚJO et al., 2013).

O Ministério da Saúde recomenda o rastreamento da anemia logo na primeira consulta de prénatal e indica as condutas necessárias, dependendo dos valores de hemoglobina. Somente não há indicação de suplementação de ferro, caso a gestante possua valor de hemoglobina maior que $11 \mathrm{mg} / \mathrm{dl}$ e não tenha fatores de risco (dieta com pouco ferro, vitaminas ou minerais; perda de sangue decorrente de cirurgia ou lesão; doença grave ou de longo prazo como câncer, diabetes, doença nos rins, artrite reumatoide, aids, doença inflamatória do intestino, doença no fígado, insuficiência cardíaca e doença na tireoide; infecções de longo prazo; histórico familiar de anemia herdada, como talassemia e anemia falciforme) (MS, 2013).

Mesmo que a gestante apresente valor de hemoglobina maior que $11 \mathrm{mg} / \mathrm{dl}$, mas possua pelo menos um fator de risco, é indicada a suplementação preventiva de 1 comprimido com 200 mg de sulfato ferroso até o final da gestação. Valor de hemoglobina menor que $11 \mathrm{mg} / \mathrm{dl}$ deve-se administrar 5 comprimidos com $40 \mathrm{mg}$ de sulfato ferroso por dia. Entretanto, essa recomendação assume a frequência de efeitos gastrointestinais causados pela suplementação (MS, 2013).

No caso do ácido fólico, não há recomendações para dosagens séricas, somente é adotado a estratégia de suplementação profilática. Entretanto, existem duas fontes de recomendações do Ministério da Saúde e que divergem entre si. Nos Cadernos de Atenção ao Pré-natal de Baixo Risco se recomenda a suplementação de $5 \mathrm{mg}$ por dia de ácido fólico, pelo menos 3 meses antes da gestação e durante o primeiro trimestre gestacional. Já no Programa Nacional de Suplementação de Ferro, que utiliza a mesma recomendação indicada pela OMS, sugere 400 
$\mu$ g, porém 30 dias antes da concepção e diariamente até o final da gestação (MS, 2013; BRASIL, 2013).

Entretanto, os níveis séricos de ácido fólico encontrados no presente estudo, levantam uma questão importante que já é discutida na literatura internacional. Encontramos 2 gestantes com deficiência dessa vitamina, mas com valor sérico muito próximo do ponto de corte; as demais participantes apresentaram valores relativamente altos. A suplementação de ácido fólico tem o objetivo de prevenir defeitos no tudo neural no bebê e anemia megaloblástica em mulheres em idade reprodutiva e no início da gravidez (WHO, 2015). Porém, não existe consenso ainda sobre um valor sérico máximo que seria seguro para a saúde materna e infantil.

A mediana e intervalos interquartis para o ácido fólico encontrados no presente estudo foram ainda menores do que os valores encontrados em estudo de coorte com gestantes canadenses (mediana: 22,47mg/ml; IQ25: 21,60mg/mL - IQ75: 23,80 $\mathrm{mg} / \mathrm{mL}$ ), considerando a mensuração do ácido fólico sérico entre 12 e 16 semanas (PLUMPTRE et al., 2015).

Há um extenso debate na literatura acerca dos altos níveis de folato sérico e suas implicações para a saúde, pois grande parte dele não é metabolizado pelo organismo humano. Os estudos atribuem essas altas concentrações de ácido fólico não metabolizado ao folato sintético, que é consumido através da suplementação e da fortificação dos alimentos. E apontam associação entre o ácido fólico não metabolizado com asma, resistência periférica à insulina, obesidade, infecções no trato respiratório em crianças e risco para câncer em animais (YAJNIK et al., 2008; WHITROW et al., 2009; DWARKANATH et al., 2013; PLUMPTRE et al., 2015).

Os valores de referência para consumo diário de folato para gestantes é de $600 \mu \mathrm{g}$ (DRI’s, 2002). Contrastando com a recomendação de suplementação de ácido fólico recomendada atualmente no Brasil $(400 \mu \mathrm{g})$, observamos que a dose adotada é próxima à quantidade indicada para o consumo recomendado. Mas, ainda existe a fortificação das farinhas de trigo e 
milho, que utilizam o folato sintético e associado a suplementação profilática indicada pode ser a causa das altas concentrações de folato encontradas.

Em relação à associação entre indicadores bioquímicos do estado nutricional e características sócio demográficas, maiores frequências de deficiência de vitamina A, anemia e valores abaixo da concentração sérica mediana para folato, $\beta$-caroteno e vitamina $E$ foram observados entre gestantes mais desfavorecidas socialmente. Características como idade menor que 20 anos, menos escolaridade, ser beneficiária do bolsa família e ser chefe de família foram associadas a menores valores séricos para as vitaminas analisadas e ainda se associaram positivamente com deficiência de vitamina A e anemia.

Esses resultados evidenciam a importância de ações de incentivo à alimentação saudável integrada a programas de promoção social para maior cobertura de informações sobre formas de adquirir, preparar e consumir os alimentos, opções de compra e economia doméstica aliada à promoção de uma alimentação adequada e saudável.

Outro resultado importante encontrado no presente estudo foi a associação positiva entre consumo diário de frutas e hortaliças e concentrações séricas de $\beta$-caroteno e vitamina $\mathrm{A}$. Essas duas vitaminas estão disponíveis em fontes alimentares diferentes, o $\beta$-caroteno está presente nas frutas, hortaliças e óleos e a vitamina A em alimentos de origem animal. Porém elas estão intimamente ligadas, pois o $\beta$-caroteno faz parte do grupo dos carotenoides com atividade pró-vitamina A, portanto, sua utilização no organismo humano acontece por meio da bio-conversão do $\beta$-caroteno em vitamina A (IOM, 2000).

No entanto, as concentrações séricas de $\beta$-caroteno têm sido consideradas em inúmeros estudos como importante indicador do consumo habitual de frutas e hortaliças (IOM, 2000). No presente estudo, a associação encontrada de consumo diário de frutas e hortaliças e maiores medianas da concentração sérica de $\beta$-caroteno, confirma estudos anteriores e indica boa acurácia da avaliação da frequência de consumo desse grupo de alimentos nas gestantes 
estudadas. Além de ser indicador de consumo dietético para frutas e hortaliças, maiores concentrações séricas de $\beta$-caroteno têm sido associadas ao menor risco para muitas doenças crônicas (IOM, 2000; HE et al., 2006; BÜCHNER et al., 2010, HU et al., 2014).

Apesar dessa relação ser bem descrita na literatura, esse efeito protetor não tem sido atribuído somente aos efeitos do $\beta$-caroteno e à sua utilização como vitamina $\mathrm{A}$, mas também à presença de outros componentes encontrados em suas fontes alimentares e pelas características de estilo de vida relacionadas ao maior consumo de frutas e hortaliças (IOM, 2000).

Em estudo caso controle aninhado a uma coorte realizado no Canadá, encontrou-se associação positiva entre maiores níveis de antioxidantes, entre eles o $\beta$-caroteno, e redução do risco de pré-eclâmpsia de início precoce ( $<34$ semanas). As gestantes canadenses incluídas nesse estudo apresentaram os seguintes valores medianos (intervalo interquartil) de $\beta$-caroteno $(\mu \mathrm{mol} / \mathrm{L}): \quad 0,32(0,18-0,57)$ no grupo dos casos e $0,40(0,25-0,70)$ no grupo controle (COHEN, 2015). Os resultados do grupo controle nesse estudo canadense foram muito próximos aos resultados observados no presente estudo.

Porém, no que se refere às concentrações séricas de $\beta$-caroteno, outros estudos encontraram valores menores para níveis de $\beta$-caroteno em gestantes. Por exemplo, estudo de coorte realizado no Peru encontrou níveis médios para $\beta$-caroteno em gestantes no segundo trimestre gestacional de $0.19 \mu \mathrm{mol} / \mathrm{L}$. Esse estudo ainda comparou seus resultados ao Inquérito Nacional de Saúde e Nutrição de Mulheres Norte Americanas (2003-04) e os resultados encontrados para média de $\beta$-caroteno em gestantes participantes do estudo foi de 0,23 $\mu \mathrm{mol} / \mathrm{L}$ (HORTON et al., 2013), valores menores que os encontrados em nosso estudo.

Com relação especificamente à vitamina $\mathrm{A}$, suas funções no organismo são diversas, desde manutenção da boa visão, desenvolvimento embrionário e modulação do sistema 
imunológico. E a deficiência dessa vitamina acarreta prejuízos para a saúde, sendo a primeira manifestação clínica relacionada à visão, denominada xeroftalmia (WHO, 2009).

Em países de baixa renda a OMS estima que a prevalência de deficiência de vitamina A seja de 10 a 20\% e indica problema grave de saúde pública se a prevalência for maior que $20 \%$ e (WHO, 2009). No presente estudo, encontramos uma prevalência dentro dos valores já estimados pela OMS e próximos de um estudo com representatividade nacional - A Pesquisa Nacional de Demografia e Saúde da Criança e da Mulher de 2006 (PNDS)- onde foi avaliado prevalência de deficiência de vitamina A em mulheres em idade reprodutiva de 12,3\%. Apesar do grupo de gestantes não terem sido incluídas na PNDS de 2006, esses dados fornecem informações a respeito de deficiência para esta vitamina em amostra populacional nacional (MS, 2009).

Em relação às características sócio demográficas relacionadas a níveis séricos de vitamina $\mathrm{A}$, estudo transversal com representatividade nacional na China, utilizando os dados do Inquérito Nacional de Saúde e Nutrição 2010-2013, encontrou mais resultados relacionados à condição social e deficiência para esta vitamina. Maior renda, maior escolaridade foram significativamente associadas a maiores médias de vitamina A. Ao passo que, a prevalência de deficiência de vitamina A foi muito menor que a encontrada no nosso estudo, as gestantes chinesas estudadas apresentaram prevalência de 5,3\% para deficiência de vitamina A (YANG et al., 2016).

Também encontramos no presente estudo, associação entre consumo alimentar e características sócio demográficas. No que se refere à associação entre a frequência de consumo diário de frutas e hortaliças segundo variáveis sócio demográficas, houve maior frequência de consumo diário de frutas e hortaliças entre as gestantes com mais de 10 anos de escolaridade, no presente estudo. Em contraste, a frequência de consumo diário de produtos 
ultraprocessados foi maior entre gestantes adolescentes, primigestas e beneficiárias do programa bolsa família.

Esse resultado é semelhante ao encontrado por FIGUEIREDO et al. (2008), que estudou os fatores associados ao consumo de frutas, legumes e verduras em adultos da cidade de São Paulo, através de estudo transversal de base populacional. Os fatores associados a maior frequência de consumo de frutas, legumes e verduras foram, maior escolaridade e idade. Além disso, os autores ainda encontraram associações positivas entre maior consumo desses grupos alimentares entre mulheres que relataram ter feito dieta no último ano e também uma associação inversa entre o consumo de alimentos ricos em gorduras e açucares e consumo de frutas, legumes e verduras.

Entretanto, resultados de outro estudo mostram certa contradição com os nossos resultados, no que diz respeito ao consumo de hortaliças entre beneficiados do programa bolsa família. Em estudo transversal que avaliou o impacto do programa bolsa família na aquisição de alimentos em mais de 50 mil domicílios brasileiros, os resultados mostraram aquisição significativamente maior entre os beneficiários do programa para os grupos de carnes, raízes, tubérculos e hortaliças (MARTINS, 2013). Contudo, ainda deve-se levar em consideração as diferenças entre a forma de avaliação do consumo alimentar entre os dois estudos. No presente estudo, utilizamos instrumento para análise do consumo individual (questionário de frequência alimentar) e no estudo citado, utilizou-se análise do consumo a partir da aquisição de alimentos, por entrevista telefônica e em amostra com representatividade nacional. Portanto, há de se esperar certas divergências entre os resultados.

Entretanto, é importante também reconhecer as limitações presentes em nosso estudo. A análise transversal não possibilita a inferência causal entre as variáveis estudadas e, desta forma, os resultados devem ser interpretados com cautela. A extrapolação dos achados para gestantes do município como um todo, especialmente na área rural, exige atenção. Estudos de 
base populacional são indicados para melhor entendimento sobre as relações entre consumo alimentar, condições sociais e estado nutricional das gestantes inscritas em pré-natal da atenção básica à saúde em diferentes cenários do país. Ainda assim, com base em nosso conhecimento até o momento, o presente estudo é pioneiro ao descrever o perfil nutricional de gestantes em um município da Amazônia Ocidental Brasileira, contribuindo com informações importantes sobre condições sócio demográficas e sua relação com ocorrência de distúrbios nutricionais relevantes ao perfil de saúde materna. 


\section{8 - Conclusão}

Na presente população de estudo, características sócio demográficas foram associadas ao estado nutricional no segundo trimestre gestacional. O consumo diário de frutas e hortaliças influenciou positivamente as concentrações séricas de $\beta$-caroteno e vitamina $\mathrm{A}$ das gestantes. Esses resultados reforçam a importância de programas de promoção social integrados `as ações para incentivo à alimentação saudável visando à melhoria das condições de saúde materna. 


\section{6 - Referências}

Alberico S, Montico M, Barresi V, Monasta L, Businelli C, Soini V, et al. The role of gestational diabetes, prepregnancy body mass index and gestational weight gain on the risk of newborn macrosomia: results from a prospective multicentre study. BMC Pregnancy and Childbirth 2014;14:23.

Araújo CRMA, Uchimura TT, Fugimori E, Nishida FS, Veloso GBL, Szarfarc SC. Níveis de hemoglobina e prevalência de anemia em gestantes atendidas em unidades básicas de saúde, antes e após a fortificação das farinhas com ferro. Rev Bras Epidemiol 2013;16(2):535-45.

Artal R, O'Toole M. Guidelines of the American College of Obstetricians and Gynecologists for exercise during pregnancy and the postpartum period. Br J Sports Med. 2003;37(1):6-12.

Augusto RA, Cobayashi F, Cardoso MA. Associations between low consumption of fruits and vegetables and nutritional deficiencies in Brazilian schoolchildren. Public Health Nutr. 2014;25(5):1-10.

Brasil. Ministério da Saúde. Secretaria de Atenção à Saúde. Departamento de Atenção Básica. Programa Nacional de Suplementação de Ferro: manual de condutas gerais/Ministério da Saúde. Secretaria de Atenção à Saúde. Departamento de Atenção Básica. Brasília: Ministério da Saúde, 2013. 24 p.

Büchner FL, H. Mesquita BB, Ros MM, Overvad K, Dahm CC, Hansen L, et al. Variety in Fruit and Vegetable Consumption and the Risk of Lung Cancer in the European Prospective Investigation into Cancer and Nutrition. Cancer Epidemiol Biomarkers Prev. 2010;19(9):2278-86.

Brunst KJ, Wright RO, DiGioia K, Enlow MB, Fernandez H, Wright RJ, et al. Racial/ethnic and sociodemographic factors associated with micronutrient intakes and inadequacies among pregnant women in an urban US population. Public Health Nutr. 2014;17(9):1960-70.

Carvalhaes MABL, Martiniano ACA, Malta MB, Takito MY, Benício MHA. Atividade física em gestantes assistidas na atenção primária à saúde. Rev Saúde Pública 2013;47(5):958-67.

CDC - Centers for Disease Control and Prevention. MMWR . State-Specific Trends in Fruit and Vegetable Consumption Among Adults - United States, 2000-2009. Weekly 2010;59(35);1125-30.

Chen LW, Low YL, Fok D, Han WM, Chong YS, Gluckman P, et al. Dietary changes during pregnancy and the postpartum period in Singaporean Chinese, Malay and Indian women: the GUSTO birth cohort study. Public Health Nutr. 2013;17(9):1930-38. 
Christian P, West KP Jr, Khatry S, Katz J, Shrestha SR, Pradhan EK, et al. Night blindness of pregnancy in rural Nepal — nutritional and health risks. Int J Epidemiol. 1998;27(2):231-7.

Claro RM, Jaime PC, Lock K, Fisberg RM, Monteiro CA. Discrepância entre dados ecológicos, domiciliares e individuais sobre o consumo de frutas e hortaliças no Brasil. Cad. Saúde Pública. 2010;26(11):2168-76.

Coelho NLP, Cunha DB, Esteves APP, Lacerda EMAL, Filha MMT. Padrão de consumo alimentar gestacional e peso ao nascer. Rev Saúde Pública 2015;49(62): 1-10.

Cook JD, Flowers CH, Skikne BS. The quantitative assessment of body iron. Blood. 2003; 101(9):3359-64.

Costa KMM, Almeida WAF, Magalhães IB, Montoya R, Moura MS, Lacerda MVG. Malária em Cruzeiro do Sul (Amazônia Ocidental brasileira): análise da série histórica de 1998 a 2008. Rev Panam Salud Publica. 2010;28(5):353-60.

Crane JMG, White J, Murphy P, Burrage L, Hutchens D. The Effect of Gestational Weight Gain by Body Mass Index on Maternal and Neonatal Outcomes. J Obstet Gynaecol Can. 2009;31(1):28-35.

Crovetto M, Uauy R, Martins AP, Moubarac JC, Monteiro C. Disponibilidad de produtos alimentarios listos para el consumo em los hogares de Chile y su impacto sobre la calidad de la dieta (2006-2007). Rev Med Chile 2014;142(7):850-8.

Dode MASO, Santos IS. Fatores de risco para diabetes mellitus gestacional na coorte de nascimentos de Pelotas, Rio Grande do Sul, Brasil, 2004. Cad. Saúde Pública. 2009;25(5);1141-52.

DRIs - Dietary Reference Intakes:Estimated Average Requirements (2002). [acesso em 02 ago 2016]. Disponível em: https://fnic.nal.usda.gov/sites/fnic.nal.usda.gov/files/uploads/recommended_intakes_individua ls.pdf.

Dwarkanath P, Barzilay JR, Thomas T, Thomas A, Bhat S, Kurpad AV. High folate and low vitamin B-12 intakes during pregnancy are associated with small-for-gestational age infants in South Indian women: a prospective observational cohort study. Am J Clin Nutr 2013;98(6):1450-8.

Enomoto K, Aoki S, Toma R, Fujiwara K, Sakamaki K, Hirahara F. Pregnancy Outcomes Based on Pre-Pregnancy Body Mass Index in Japanese Women. PLoS ONE 2016;11(6):1-12. 
Ferreira HS, Moura FA, Júnior CRC. Prevalência e fatores associados à anemia em gestantes da região semi-árida do Estado de Alagoas. Rev Bras Ginecol Obstet. 2008;30(9):445-51.

Figueiredo ICR, Jaime PC, Monteiro CA. Fatores associados ao consumo de frutas, legumes e verduras em adultos da cidade de São Paulo. Rev Saúde Pública 2008;42(5):777-85.

Gomes LF, Alves AF, Sevanian A, et al. Role of $\beta 2$-glycoprotein I, LDL-, and antioxidant concentrations in hypercholesterolemic elderly subjects. Antioxid Redox Signal. 2004;6(2):237-44.

Haidar J. Prevalence of Anaemia, Deficiencies of Iron and Folic Acid and Their Determinants in Ethiopian Women. J Health PopulNutrAug. 2010;28(4):359-368.

He FJ, Nowson CA, MacGregor GA. Fruit and vegetable consumption and stroke: metaanalysis of cohort studies. Lancet. 2006;367(9507):320-26.

Hillesund ER, Bere E, Haugen Ml, Overby NC. Development of a New Nordic Diet score and its association with gestational weight gain and fetal growth - a study performed in the Norwegian Mother and Child Cohort Study (MoBa). Pub Health Nutr. 2014;17(9):1909-18.

Hu D, Huang J, Wang Y, Zhang D, Qu Y. Fruits and Vegetables Consumption and Risk of Stroke: A Meta-Analysis of Prospective. Stroke. 2014;45(6):1613-19.

Huidobro A, Prentice A, Fulford T, Parodi C, Rozowski J. Gestational diabetes, comparison of women diagnosed in second and third trimester of pregnancy with non GDM women: Analysis of a cohort study. Revista médica de Chile. 2010;138(3):316-321.

IBGE - Instituto Brasileiro de Geografia e Estatística [homepage na internet] (2014). Cidades@ [acesso em 17 set 2014]. Disponível em: <http://www.ibge.gov.br>.

IBGE - Brasileiro de Geografia e Estatística. Pesquisa de Orçamentos Familiares 2008-2009. Rio de Janeiro; 2010.

IOM (Institute of Medicine) and NRC (National Research Council). Leveraging action to support dissemination of the pregnancy weight gain guidelines: Workshop summary. Washington, DC; 2013.

Kac G, Velásquez-Meléndez G. Ganho de peso gestacional e macrossomia em uma coorte de mães e filhos. J Pediatr. 2005;81(1):47-53.

Koury HCF. Estado Nutricional de mulheres, mães de crianças menores de cinco anos, Jordão, Acre, Brasil. [tese]. São Paulo: Faculdade de Saúde Pública da USP; 2010. 
Kramer MS. Determinants of low birth weight: methodological assessment and meta-analysis. Bulletin of the World Health Organization. 1987;65(5):663-737.

Kraschnewski JL, Chuang CH. "Eating for Two": Excessive Gestational Weight Gain and the Need to Change Social Norms. Women's Health Issues. 2014;24(3):257-9.

Lacerda EMA, Kac G, Cunha CB, Leal MC. Consumo alimentar na gestação e no pós-parto segundo cor da pele no município do Rio de Janeiro. Rev Saúde Pública. 2007;41(6):985-94.

Li N, Liu E, Guo J, Pan L, Li B, Wang P, et al. Maternal Prepregnancy Body Mass Index and Gestational Weight Gain on Pregnancy Outcomes. PLoS ONE. 2013;8(12):1-12.

Louzada MLC, Martins APB, Canella DS, Baraldi LG, Levy RB, Claro RM, et al. Impact of ultra-processed foods on micronutriente content in the Brazilian diet. Rev Saúde Pública. 2015;49(45):1-8.

Martínez SE, Baraldi LG, Louzada MLC, Moubarac JC, Mozaffarian D, Monteiro CA. Ultraprocessed foods and added sugars in the US diet: evidence from a nationally representative cross-sectional study. BMJ Open 2016;693):1-9.

Martins APB, Levy RB, Claro RM, Moubarac JC, Monteiro CA. Participação crescente de produtos ultraprocessados na dieta brasileira (1987-2009). Rev Saúde Pública. 2013;47(4):656-65.

Martins APB, Benicio MHA. (2011). Influência do consumo alimentar na gestação sobre a retenção de peso pós-parto. Rev Saúde Pública;45(5):870-77.

Miranda AE, Pinto VM, Szwarcwald CL, Golub ET, et al. Prevalence and correlates of preterm labor among young parturient women attending public hospitals in Brazil. Rev Panam Salud Publica. 2012;32(5):330-4.

Monteiro CA, Levy RB, Claro RM, Castro IRR, Cannon G. A new classification of foods based on the extent and purpose of their processing. Cad. Saúde Pública, Rio de Janeiro, 2010;26(11):2039-49.

Monteiro CA, Levy RB, Claro RM, Castro IRR, Cannon G. Increasing consumption of ultraprocessed foods and likely impact on human health: evidence from Brazil. Public Health Nutr. 2011;14(1):5-13.

Monteiro CA, Cannon G, Levy RB, Moubarac J-C, Jaime P, Martins AP, Canella D, et al . NOVA. A estrela brilha. [Classificação dos alimentos. Saúde Pública]. World Nutrition Janeiro-Março 2016;7(1-3):28-40. 
Monteiro JP, Junior JC. Caminhos da Nutrição e Terapia Nutricional: da Concepção à Adolescência. Rio de Janeiro: Editora Guanabara Hoogan, 2007.

Mozaffarian D, Hao T, Rimm EB, Willett WC, Hu FB. Changes in Diet and Lifestyle and Long-Term Weight Gain in Women and Men. N Engl J Med. 2011;364(25):2392-404.

MS - Ministério da Saúde (2009). PNDS 2006: Pesquisa Nacional de Demografia e Saúde da Criança e da Mulher. Brasília: MS.

MS - Ministério da Saúde. Secretaria de Atenção à Saúde. Departamento de Atenção Básica. Guia alimentar para a população - 2.ed. - Brasília, 2014.

MS - Ministério da Saúde [homepage da internet] (2013). DATASUS - Tecnologia da informação a serviço do SUS [acesso em 12 Jul 2013]. Brasília; MS. Disponível em: $<$ http://tabnet.datasus.gov.br/.

MS - Ministério da Saúde [homepage da internet] (2013). DATASUS - Tecnologia da informação a serviço do SUS [acesso em 14 Jul 2013]. Brasília; MS. Disponível em: http://dab.saude.gov.br/portaldab/historico_cobertura_sf.php.

MS - Ministério da Saúde. Atenção ao Pré-Natal de Baixo Risco - Série A. Normas e Manuais Técnicos. Cadernos de Atenção Básica, n 32. Brasília; 2013.

Plumptre L, Masih SP, Ly A, Aufreiter S, Sohn KJ, Croxford R, et al. High concentrations of folate and unmetabolized folic acid in a cohort of pregnant Canadian women and umbilical cord blood. Am J Clin Nutr 2015;102(4):848- 57.

Popkin, BM. Rank Prize Lecture Contemporary nutritional transition: determinants of diet and its impact on body composition. Proceedings of the Nutrition Society. 2011;70:82-91.

Cappuccio FP, Rink E, Perkins-Porras L, McKay C, Hilton S, Steptoe A. Estimation of fruit and vegetable intake using a two-item dietary questionnaire: a potential tool for primary health care workers. Nutr Metab Cardiovasc Dis. 2003;13(1):12-9.

Pedersen M, Schoket B, Godschalk RW, Wright J, Stedingk H, Törnqvist M, et al. Bulky DNA Adducts in Cord Blood, Maternal Fruit-and-Vegetable Consumption, and Birth Weight in a European Mother-Child Study. Environ Health Perspect. 2013;121(10):1200-6.

OMS - Organização Mundial da Saúde. Diretriz: Suplementação diária de ferro e ácido fólico em gestantes. Genebra; 2013.

Qing X, Ying GZ, Ming LL, Lu W, Qian Z, Yue T. The Association of Maternal Body Composition and Dietary Intake with the Risk of Gestational Diabetes Mellitus during the 
Second Trimester in a Cohort of Chinese Pregnant Women. Biomed Environ. Sci, 2016;29(1):1-11.

Sachdeva S, Sachdev TR, Sachdeva R. Increasing Fruit and Vegetable Consumption: Challenges and Opportunities. Indian J Community Med. 2013;38(4):192-7.

Santos Q, Sichieri R, Marchioni DML, Verly EJ. Brazilian pregnant and lactating women do not change their food intake to meet nutritional goals. BMC Pregnancy and Child birth. 2014;14(186):1-7.

Seligman LC, Duncan BB, Branchtein L, Mengue SS, Schmidt MI. Obesity and gestational weight gain: cesarean delivery and labor complications. Rev SaúdePública. 2006;40(3):45755.

Vandevijvere S, Amsalkhir S, Oyen HV, Egli I, Moreno-Reyes R. Iron status and its determinants in a nationally representative sample of pregnant women. J AcadNutr Diet. 2013;113(5):659-66.

Vitolo MR, Boscaini C, Bortolini GA. Baixa escolaridade como fator limitante para o combate à anemia entre gestantes. Rev Bras Ginecol Obstet. 2006;28(6):331-9.

Vítolo MR. Nutrição: da gestação ao envelhecimento. Rio de Janeiro: Editora Rubio; 2008.

Vítolo MR, Bueno MSF, Gama CM. Impacto de um programa de orientação dietética sobre a velocidade de ganho de peso de gestantes atendidas em unidades de saúde. Rev Bras Ginecol Obste 2011;33(1);13-9.

Wang DD,Leung CW, Li Yanping, Ding EL, Chiuve SE, Hu FB et al. Trends in Dietary Quality Among Adults in the United States, 1999 Through 2010. JAMA Intern Med. 2014;174(10):1587-95.

Whitrow MJ, Moore VM, Rumbold AR, Davies MJ. Effect of Supplemental Folic Acid in Pregnancy on Childhood Asthma: A Prospective Birth Cohort Study. Am J Epidemiol 2009;170(12):1486- 93

WHO - world Health Organization Collaborative study. Maternal anthropometry and pregnancy outcomes. Geneva; 1995.

WHO - World Health Organization. Indicators for assessing Vitamin A Deficiency and their application in monitoring and avaluating intervention programmes. Micronutrient Series. Geneva; 1996.

WHO - World Health Organization. Iron Deficiency Anaemia Assessment, Prevention, and Control. A guide for programme managers. Geneva; 2001. 
WHO - World Health Organization. World report: reducing risks, promoting healthy life. Geneva; 2002.

WHO - World Health Organization. Diet, Nutrition and the Prevention of Chronic Diseases. Geneva; 2003.

WHO - World Health Organization. Global prevalence of vitamin A deficiency in populations at risk 1995-2005. WHO Global DatabaseonVitamin A Deficiency. Geneva; 2009.

WHO - World Health Organization. Guideline: Daily iron and folic acid supplementation in pregnant women. Geneva; 2012.

WHO - World Health Organization. Guideline: Optimal serum and red blood cell folate concentrations in women of reproductive age for prevention of neural tube defects. Geneva; 2015 .

Wylie BJ, Kalilani-Phiri L, Madanitsa M, Membe G, Nyirenda O, Mawindo P, et al. Gestational age assessment in malaria pregnancy cohorts: a prospective ultrasound demonstration project in Malawi. Malar J. 2013;12(183):1-10.

Yajnik CS, Despande SS, Jackson AA, Refsum H, Rao S, Fischer DJ, et al. Vitamin B12 and folate concentrations during pregnancy and insulin resistance in the offspring: the Pune Maternal Nutrition Stud. Diabetologia. 2008;51(1):29-38.

Yang C, Chen J, Liu Z, Yun C, Piao J, Yang X. Prevalence and influence factors of vitamin A deficiency of Chinese pregnant women. Nutrition Journal. 2016;15(12):1-7.

Zhang C, Tobias DK, Chavarro JE, Bao W, Wang D, Ley SH. Adherence to healthy lifestyle and risk of gestational diabetes mellitus: prospective cohort Study. BMJ 2014;349(5450):111 . 
7 - Anexos 
Anexo 1

Ficha para rastreamento das gestantes pelos postos de saúde 
Anexo 2

Questionário sócio demográfico e de história de saúde 
Anexo 3

Questionário da avaliação clínica para dados antropométricos, bioquímicos, de consumo alimentar e ultrassonografia 
Anexo 4

Termo de Consentimento Livre e esclarecido 
8 - Currículos Lattes 
